\title{
An investigation of methods for injecting emissions from boreal wildfires using WRF-Chem during ARCTAS
}

\author{
W. R. Sessions ${ }^{1, *}$, H. E. Fuelberg ${ }^{1}$, R. A. Kahn ${ }^{2}$, and D. M. Winker ${ }^{3}$ \\ ${ }^{1}$ Department of Meteorology, Florida State University, Tallahassee, Florida, USA \\ ${ }^{2}$ Jet Propulsion Laboratory, California Institute of Technology, Pasadena, California, USA \\ ${ }^{3}$ NASA Goddard Space Flight Center, Hampton Virginia, USA \\ * present address: Naval Research Laboratory, Monterey, California, USA
}

Received: 18 September 2010 - Published in Atmos. Chem. Phys. Discuss.: 8 November 2010

Revised: 2 June 2011 - Accepted: 7 June 2011 - Published: 21 June 2011

\begin{abstract}
The Weather Research and Forecasting Model (WRF) is considered a "next generation" mesoscale meteorology model. The inclusion of a chemistry module (WRFChem) allows transport simulations of chemical and aerosol species such as those observed during NASA's Arctic Research of the Composition of the Troposphere from Aircraft and Satellites (ARCTAS) in 2008. The ARCTAS summer deployment phase during June and July coincided with large boreal wildfires in Saskatchewan and Eastern Russia.

One of the most important aspects of simulating wildfire plume transport is the height at which emissions are injected. WRF-Chem contains an integrated one-dimensional plume rise model to determine the appropriate injection layer. The plume rise model accounts for thermal buoyancy associated with fires and local atmospheric stability. This paper describes a case study of a 10 day period during the Spring phase of ARCTAS. It compares results from the plume model against those of two more traditional injection methods: Injecting within the planetary boundary layer, and in a layer $3-5 \mathrm{~km}$ above ground level. Fire locations are satellite derived from the GOES Wildfire Automated Biomass Burning Algorithm (WF_ABBA) and the MODIS thermal hotspot detection. Two methods for preprocessing these fire data are compared: The prep_chem_sources method included with WRF-Chem, and the Naval Research Laboratory's Fire Locating and Monitoring of Burning Emissions (FLAMBE). Results from the simulations are compared with satellitederived products from the AIRS, MISR and CALIOP sensors.
\end{abstract}

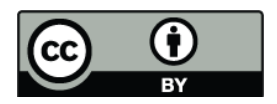

Correspondence to: H. E. Fuelberg (hfuelberg@fsu.edu)
When FLAMBE provides input to the 1-D plume rise model, the resulting injection heights exhibit the best agreement with satellite-observed injection heights. The FLAMBE-derived heights are more realistic than those utilizing prep_chem_sources. Conversely, when the planetary boundary layer or the $3-5 \mathrm{~km}$ a.g.l. layer were filled with emissions, the resulting injection heights exhibit less agreement with observed plume heights. Results indicate that differences in injection heights produce different transport pathways. These differences are especially pronounced in area of strong vertical wind shear and when the integration period is long.

\section{Introduction}

Many processes affect the polar regions before the more populated middle and lower latitudes (Arctic Climate Impact Assessment, 2004). The Arctic's lack of large population centers fosters the falsehood that it is a pristine environment. However, the Arctic has experienced large scale reported pollution events since the 18th century (Garrett, 2006), with pilots describing visibility reducing haze during the 1950's (Mitchell, 1957). Understanding the mechanisms leading to pollution transport into the Arctic and its chemical composition is pivotal to assessing the threat of climate change.

Arctic pollution occurs seasonally, with the greatest episodic increases in particle concentration during the winter and spring months (Quinn et al., 2007; Shaw, 1995; Barrie, 1986). These pollution events, often called "Arctic Haze", are observed after polar sunrise and can persist until May. The haze consists mainly of sulfate and organics, with $\mathrm{NO}_{\mathrm{x}}$, volatile organic compounds, nitrates, black carbon (BC), dust aerosols, and ammonium also present (e.g., Quinn

Published by Copernicus Publications on behalf of the European Geosciences Union. 
et al., 2007; Solberg et al., 1996). Although these species mostly are transported from outside the Arctic, they represent an important forcing to the Arctic's radiative balance. Greenhouse gases such as carbon dioxide trap thermal radiation in the lower troposphere (Arctic Climate Impact Assessment, 2004). Black carbon deposits on snow and ice sheets decrease the surface albedo (Hansen and Nazarenko, 2004; Koch and Hansen, 2005; McConnell et al., 2007). Direct atmospheric warming occurs because some aerosols absorb in the visible and thermal spectrum (Sharma et al., 2006; Quinn et al., 2008).

Chemical transport models play a critical role in understanding source-receptor relationships between pollutants and the Arctic. Transport models can be functionally subdivided into "online" and "offline" categories depending on their integration with a host meteorological model. Offline models calculate transport based on wind data generated by another model, and sometimes include mechanisms for simulating meso- and micro-scale processes such as convection and turbulence. Since offline transport models are run post facto, they cannot feed back to the meteorological fields effects such as radiative absorption by aerosols or latent heat release from chemical bonding. The FLEXPART Lagrangian particle dispersion model (Stohl et al., 1998, 2005) is an example of an offline model that uses winds from a separate meteorological model. Online chemical transport models consist of a chemical module within the meteorological model, with both components running simultaneously and feeding information back and forth between the two. Thus, online models attempt to provide improved representations of interactions between meteorology and the chemistry and physics of trace species and aerosol particles. For example, the Weather Research and Forecasting Model with Chemistry (WRF-Chem) (Grell et al., 2005) incorporates radiative and chemical feedbacks into the atmospheric energy budget that an offline model cannot do. A detailed description of WRFChem can be found in Grell et al. (2005), with study specific details provided in Sect. 2 below.

Model-derived data have been used extensively to characterize pollution pathways to the Arctic. Stohl (2006) and Law and Stohl (2007) used FLEXPART to develop a transport climatology that revealed three primary mechanisms for transport to the Arctic's lower troposphere: ascent outside the Arctic followed by settling (primarily from North America, Asia and Europe), low level transport with ascent within the Arctic (primarily from Europe), and continuous low level transport (primarily from Europe during winter). Klonecki et al. (2003) showed that transport into the Arctic is consistent with isentropic flow, i.e., ascent along isentropic surfaces as a plume moves north. Grell et al. (2011) included a plume rise algorithm for wildfires in WRF-Chem and examined the impact of intense wildfires during the 2004 Alaska wildfire season on weather simulations using model resolutions of $10 \mathrm{~km}$ and $2 \mathrm{~km}$.
Boreal wildfires recently have been recognized as an important seasonal source of pollutants into the Arctic (Warneke et al., 2009; Hegg et al., 2009; Kasischke et al., 2005; Andreae and Merlet, 2001; Crutzen and Andreae, 1990), and they can produce hemispheric influences (Wotawa et al., 2006; Damoah et al., 2004; van der Werf et al., 2003). Andreae et al. (2004) showed that the large aerosol loading from fires suppresses wet deposition, significantly enhancing aerosol transport. Although the total forest area burned within the tropics exceeds that of boreal fires, boreal fires have been increasing steadily in recent decades (Stocks et al., 2003; Lavouè et al., 2000). Boreal forest fires have a greater contribution of smoldering combustion and make relatively stronger contributions to emissions of aerosol particles and products of incomplete combustion (Cofer et al., 1996). Although they currently contain less burn area than tropical forest fires, boreal forests have denser growth and rich surface layers that increase the available organic fuel and emissions (Kasischke et al., 2005; Kasischke and Bruhwiler, 2002). The convective motions that often occur with wildfires increase the likelihood that emissions will be lofted to the faster winds of the free atmosphere. While small emission sources with minimal excess energy often are turbulently mixed into the PBL (Labonne et al., 2007), plumes from crown fires have been observed to maintain more cohesive structures that extend into the free troposphere (Lavouè et al., 2000; Cofer et al., 1996; Generoso et al., 2007). This process relies on sensible heat flux and latent heat of condensation to enhance a plume's buoyancy (Freitas et al., 2007). Some previous research has suggested a linear correlation between fire intensity and emission injection height (Lavouè et al., 2000). Plumes can escape the boundary layer (Val Martin et al., 2010; Kahn et al., 2008) and have been observed to accumulate in layers of relative stability (e.g., Kahn et al., 2007). The wildfire smoke can even reach the lower stratosphere during cases of strong pyroconvection (e.g., Fromm, 2008; Trentmann et al., 2006). Releasing simulated emissions at appropriate altitudes has been a crucial and difficult problem to successfully modeling plume transport (e.g., Colarco et al., 2004; Westphal and Toon, 1991).

Near source vertical plume distributions (i.e., "injection heights") often have been represented in transport models using empirical or arbitrary procedures (Freitas et al., 2007; Turquety et al., 2007). These methods have included linearly filling estimated injection columns (e.g., Damoah et al., 2004; Forster et al., 2001; Spichtinger et al., 2001), restricting emissions to surface layers (Leung et al., 2007; Lamarque et al., 2003), assumed turbulent mixing by filling the planetary boundary layer (Fisher et al., 2010; Leung et al., 2007; Hyer et al., 2007), using an empirical relationship between the injection height and fire intensity (Lavouè et al., 2000; Wang et al., 2006), release in the upper atmosphere as occurs in pyroconvection (Hyer et al., 2007), or more complex distributions with emissions unevenly released at varying heights (Leung et al., 2007). Explicitly resolving 
three-dimensional microscale plume properties over large areas is limited by current computational capabilities. To avoid such constraints, Freitas et al. (2007) embedded a onedimensional (1-D) plume-rise model at each location of a coarse scale grid to parameterize injection heights. Based on Lantham (1994), this 1-D system uses meteorological modelderived column data to calculate atmospheric stability. Once vertical motion decreases to less than $1 \mathrm{~m} \mathrm{~s}^{-1}$, a near equilibrium state is assumed, and the injection height is defined.

The Freitas et al. (2007) 1-D plume-rise model has been incorporated into WRF-Chem. This inclusion is important since many transport models rely on coarse horizontal scale (e.g., 45-200 km) global meteorological models for their transport parameters (e.g., Stohl et al., 2007; Damoah et al., 2004). Although these models generally have produced satisfactory results, global models do compound interpolation error both spatially and temporally and can produce nonphysical results within transport models (Stohl et al., 1995, 2004). On the other hand, WRF-Chem, being an Eulerian model, has numerical diffusion limitations at the resolution we are running $(45 \mathrm{~km})$. We acknowledge whatever limitations this may produce in our simulations. The importance of increasing horizontal model resolution from $36 \mathrm{~km}$, to $12 \mathrm{~km}$, and then to $4 \mathrm{~km}$ has been shown to increase forecast skill (Mass et al., 2002). To our knowledge the effects of increasing resolution from the global scale down to much smaller scales has not been reported in the literature; however, the national meteorological centers (e.g., National Centers for Environmental Prediction (NCEP) and European Center for Medium Range Weather Forecasting (ECMWF) have been running their global models at increasingly higher resolutions as computing resources permit.

The present study evaluates the ability of WRF-Chem's 1D plume rise model to diagnose the injection heights of fire emissions during NASA's Arctic Research of the Composition of the Troposphere from Aircraft and Satellites (ARCTAS) campaign during 2008 (Jacob et al., 2010). Since it considers only a 10 day period, it is a case study that complements previous research that has examined longer periods (e.g., Freitas et al., 2007; Val Martin et al., 2010; Grell et al., 2011; Labonne et al., 2007). Two preprocessing methods for preparing biomass burning emissions are investigated, the standard WRF-Chem package (Prep_chem_sources) and the Naval Research Laboratory's (NRL) Fire Locating and Monitoring of Burning Emissions (FLAMBE). We compare injection heights from the plume rise model with those where pollutants are injected only within the boundary layer or between $3-5 \mathrm{~km}$ above the surface. We also evaluate the ability of WRF-Chem to model the downwind evolution of fire plumes. Finally, model-derived plume characteristics are compared with those remotely observed by satellite sensors.

\section{Data and methodology}

\subsection{Numerical simulations}

Our research domain was centered on the North Pole, extended over most of the Northern Hemisphere, and used a polar stereographic projection (Fig. 1a). Since the goal was to explore the transport of emissions into the Arctic, the domain encompassed major historic source regions of biomass burning and anthropogenic emissions, including Russia, Alaska, Canada, and eastern Europe. These locations were far enough from the domain boundary to minimize lateral boundary error (Warner et al., 1997).

The ARCTAS summer phase during June and July 2008 coincided with boreal wildfires in eastern Asia and Saskatchewan. Most of the observed fires in eastern Asia were located on the Stanovoy Mountain range (labeled "A" in Fig. 1c) and the Dzhugdzhur coastal range (labeled "B") that are located west of the Sea of Okhotsk (Fig. 1b). Much of the Stanovoy range is at 700 to $1500 \mathrm{~m}$ m.s.l. (Fig. 1c). A Siberian fire outbreak from 28-30 June (Fig. 1b) produced emissions that were observed to pool over Asia prior to being transported over the Pacific Ocean and into the Arctic. Fires also occurred during this period in the Canadian provinces of Saskatchewan and the Northwest Territories, producing outflow to Greenland and Europe; however, these fires were not as intense or widespread as those in Asia. Our ten-day computational period encompassed this period of active Asian and Canadian fires between 28 June-8 July 2008 .

Transport simulations were performed using WRF-Chem version 3.1.1 which is based on the Advanced Research WRF (ARW) (Skamarock et al., 2008). WRF is a nonhydrostatic, mesoscale model utilizing 2nd and 3rd order Runge-Kutta time integration schemes. WRF-Chem supports several physical, dynamic, and chemical parameterizations (Grell et al., 2005). To simulate turbulent chemical transport within the boundary layer, our configuration used the Yonsei University PBL parameterization which diagnoses PBL height from the buoyancy profile (Hong et al., 2006). We used a horizontal grid resolution of $45 \mathrm{~km}$ with 50 vertical sigma levels packed near the surface and mean jet stream levels. Further information about model configuration is provided in Table 1 .

Meteorological initial and boundary conditions for the WRF-Chem simulations were interpolated from the NCEP Global Forecast System (GFS; Global Climate and Weather Modeling Branch, 2003). GFS is a spectral model operating on an approximate $0.5 \times 0.5 \mathrm{deg}$ Gaussian grid with 64 vertical sigma levels.

The gas phase chemical mechanisms in WRF-Chem originally were developed for the Regional Acid Deposition Model, version 2 (RADM2, Chang et al., 1991). Although WRF-Chem can simulate dozens of organic and inorganic species, we focused on carbon monoxide (CO) as a gas phase tracer of the biomass burning plumes. Initial and boundary 
a)
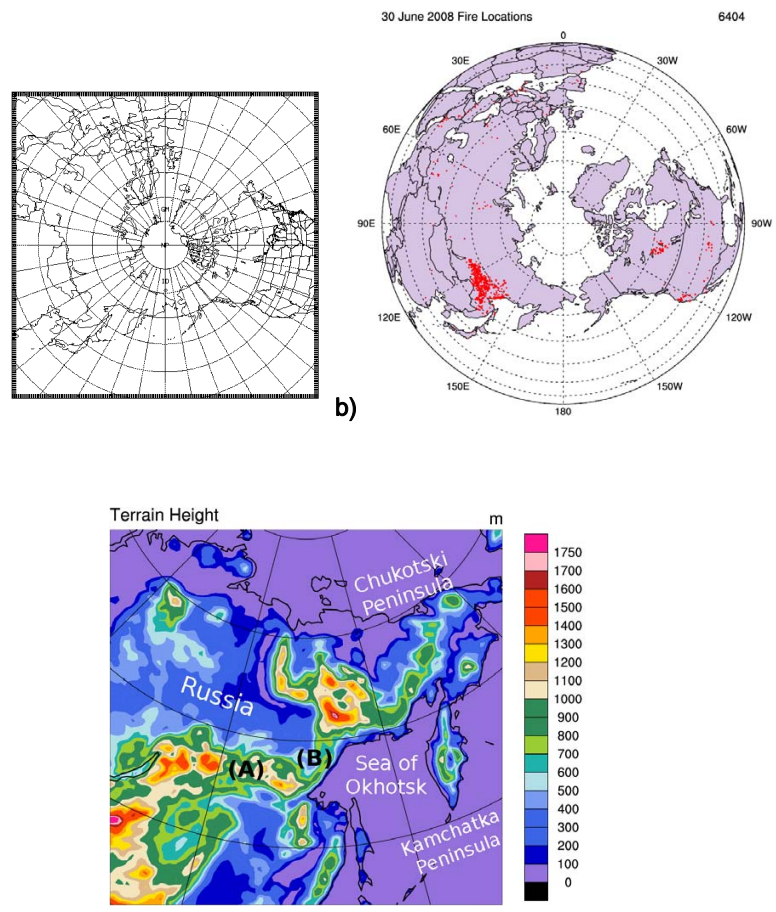

c)

Fig. 1. (a) WRF-Chem domain, (b) satellite-derived fire locations on 30 June 2008 during major Siberian and Canadian fire outbreaks, and (c) topographic map of northeastern Asia. Observed fires primarily were near the Stanavoy Mountains (labeled A) and the Dzhugdzhur coastal range (labeled B) west of the Sea of Okhotsk.

conditions were represented by an idealized, northern hemispheric, mid-latitude, clean environmental profile from the NOAA Aeronomy Lab Regional Oxidant Model (NALROM, Liu et al., 1996). The parameterization of aerosols was incorporated from the Modal Aerosol Dynamics Model for Europe (MADE, Ackermann et al., 1998), with the Secondary Organic Aerosol Model (SORGAM) simulating the formation of secondary organic aerosols (Schell et al., 2001).

Global emissions were incorporated into WRF-Chem. Anthropogenic emissions were based on the $0.5 \times 0.5$ deg REanalysis of the TROpospheric (RETRO) chemical composition dataset (Schultz et al., 2008; http://retro.enes.org/index. shtml). Biomass burning emissions were based on satellite retrievals. The GOES Wildfire Automated Biomass Burning Algorithm (WF_ABBA) relies on the method of Matson and Dozier (1981) to identify sub-pixel anomalies in the thermal infrared band that are associated with fires. WF_ABBA provides half-hourly hot-spot identification for the majority of the Western Hemisphere. Outside of the GOES domain, the MOderate-Resolution Imaging Spectrometer (MODIS) sensors on the Terra and Aqua satellites provide global scale fire detection using the sensor's infrared bands (Justice et al., 2002; Giglio et al., 2003). MODIS identifies fires utilizing a method similar to WF_ABBA, but MODIS can de-
Table 1. WRF-Chem domain and parameterization settings used in this study. Details about WRF-Chem can be found in Grell et al. (2005).

\begin{tabular}{ll}
\hline Field & Setting \\
\hline Horizontal Resolution & $45 \mathrm{~km}$ \\
Vertical Levels & 50 non-linear sigma levels \\
Shortwave Radiation & Goddard (Chou and Suarez, 1994) \\
Longwave Radiation & RRTM (Mlawer et al., 1997) \\
Surface Layer Physics & MM5 Similarity (Paulson, 1970, \\
& Dyer and Hicks, 1970) \\
Land Surface Physics & Noah (Ek et al., 2003) \\
Planetary Boundary Layer & YSU (Hong et al., 2006) \\
Cumulus Parameterization & Grell-Devenyi (Grell and Devenyi, 2002) \\
\hline
\end{tabular}

tect smaller fires than GOES due to its higher spatial resolution. Since Terra and Aqua fly in near-polar orbits with ascending and descending equator crossings at 01:30 and 10:30 LST, respectively, the temporal resolution of their active fire products is limited, with only one global image being available each day. The MODIS products were available from http://rapidfire.sci.gsfc.nasa.gov/.

Two preprocessing methods for inserting the satellite-derived fire locations into WRF-Chem were tested. WRF-Chem's officially supported package, called prep_chem_sources, reads the fire location data and maps them to the WRF domain. (WRF-Chem Users's Guide, 2011; available at http://ruc.noaa.gov/wrf/WG11/Users_guide.pdf). When MODIS fire data are used, the locations are fixed during the $24 \mathrm{~h}$ period. An area of $228000 \mathrm{~m}^{2}$ per fire grid point is assumed. Emission factors from Andreae and Merlet (2001) account for variations in surface types, with the emissions released uniformly during each $24 \mathrm{~h}$ period.

The second preprocessor of wildfire locations is based on the Fire Locating and Modeling of Biomass Burning Emissions (FLAMBE) dataset (Reid et al., 2009; http://www. nrlmry.navy.mil/flambe/). FLAMBE provides carbon and aerosol emissions at hourly intervals. Fire data again are from the WF_ABBA and MODIS active fire products. Emissions are calculated by matching fire locations to a $1 \mathrm{~km}$ land use database. Although prep_chem_sources releases emissions at a constant rate during a $24 \mathrm{~h}$ period, FLAMBE simulates diurnal variability by releasing 90 percent of the emissions between 09:00-19:00 LST (local standard time). The reported burn area also varies temporally, splitting the estimated $625000 \mathrm{~m}^{2}$ burn area per fire into 24 hourly segments that are proportional to diurnal fire activity (i.e., a larger burn area in the afternoon than overnight). This approach is useful due to MODIS's poor temporal resolution. Hourly FLAMBE emissions were converted and re-gridded to be consistent with our WRF-Chem configuration. 
The smoke plume rise associated with biomass burning is parameterized using a simple one-dimensional timedependent entrainment plume model (Latham, 1994; Freitas et al., 2006, 2007) that is embedded in each column of the 3-D WRF-Chem model. The scheme was developed for use in low resolution atmospheric chemistry models, e.g., global models, but also can be used at higher resolutions. The plume model interactively provides the smoke injection height at which trace gases and aerosols are released and then transported and dispersed by the prevailing winds of the host model. The plume rise model is based on the continuity equations for water in all phases, the vertical equation of motion, and the first law of thermodynamics. To reduce the limitations of 1-D simulation, the model includes parameterizations for autoconversion (Berry, 1968), ice formation (Ogura and Takahashi, 1971), cloud microphysics, and accretion (Kessler, 1969), with entrainment defined as proportional to vertical velocity. To estimate heat flux, fires are divided into four surface categories based on WRF's land use dataset: Savanna, grassland, tropical and extra-tropical forests. Simulated atmospheric sounding data for the plume rise model are computed every hour at each grid point containing an active fire. Updated emission layers are produced based on column stability.

The lower boundary condition of the injection layer is based on a virtual source of buoyancy placed below the model surface (Turner, 1973; Latham, 1994; Freitas et al., 2007). The final height reached by a plume is controlled by the thermodynamic stability of the atmospheric environment and the surface heat flux release from the fire (Freitas et al., 2010). The final rise of the plume is determined by the height at which the vertical velocity of the in-plume air parcel is less than $1 \mathrm{~m} \mathrm{~s}^{-1}$. Results of using the plume rise model in WRF-Chem during the 2004 Alaska wildfire season are described by Grell et al., 2011). Entrainment of environmental air into the plume results in rapid cooling, causing near-source plume temperatures to be only slightly warmer than the environment. Buoyancy also is affected by radiative cooling and latent heat release if the plume reaches the lifting condensation level (LCL). Strong horizontal winds can lead to a less vertical plume, enhance the entrainment processes, and prevent the plume from reaching the LCL (Freitas et al., 2010; Val Martin et al., 2010). Strong winds also produce enhanced turbulent mixing in the boundary layer. These effects are most pronounced for small fires occurring in humid environments (Freitas et al., 2010). Regardless, the influence of horizontal wind on vertical plume development is not considered in the WRF-Chem 3.1.1 plume rise model, but will be included in later versions.

To evaluate the efficacy of the WRF-Chem plume rise model, we made additional simulations using two traditional column filling emission schemes: emissions throughout the PBL, and emissions throughout the $3-5 \mathrm{~km}$ layer. These methods previously have been used to estimate turbulently mixed surface emissions and lofted emissions, respectively.
Since the PBL height varies by location and time of day, approximate heights were calculated using a separate, initial WRF run. The emissions then were distributed within the PBL by the chemically enabled WRF-Chem runs.

\subsection{Verification methods}

Observations of near-source injection heights as well as horizontal and vertical plume specifications after long range transport were used to assess the simulations. To evaluate WRF-Chem's near-source injection heights, we used stereo height products from the Multi-angle Imaging SpectoRadiometer (MISR, Muller et al., 2002; Diner et al., 1999; Kahn et al., 2007). Plumes were processed and digitized as part of NASA's MISR Plume Height Climatology Project. Using the MISR INteractive eXplorer (MINX) software (Nelson et al., 2008), 250 plumes were identified over Siberia and Canada during our ten day model integration period (http://misr.jpl.nasa.gov/getData/accessData/ MisrMinxPlumes/index.cfm). To compare the MISR-derived plumes with those from WRF-Chem, we matched maximum plume heights with the nearest model grid point in space and time. Given the limitations of model resolution, if multiple plumes were located within the same WRF-Chem grid cell, the average of their heights was assigned.

We used the total column carbon monoxide (CO) product from the Atmospheric InfraRed Sounder (AIRS) on Aqua to evaluate the downwind evolution of the simulated plumes. Several previous studies have employed AIRS CO to investigate the horizontal extent of combustion products (e.g., Peffers et al., 2009; Zhang et al., 2008; Stohl et al., 2007). AIRS provides $\sim 70$ percent coverage of the Earth's surface on a daily basis (McMillan et al., 2005). The AIRS $\mathrm{CO}$ retrieval algorithm uses a maximum likelihood (or some variant) that incorporates a prior estimate. The prior estimate dominates retrieval values at the surface. Previous aircraft-based studies have shown non-polar retrieval uncertainty to be $15-20 \%$ at $500 \mathrm{hPa}$ (McMillan et al., 2005). The CO products have not been validated over polar regions, suggesting uncertainties of $10-50 \%$ at $500 \mathrm{hPa}$ (http://disc.sci.gsfc.nasa.gov/AIRS/documentation/v5_docs/ AIRS_V5_Release_User_Docs/V5_CalVal_Status_Summary. pdf). AIRS CO data at very high latitudes currently exhibit a low bias (J. Warner, personal communication, 2010). Filtering procedures were applied to the retrievals to increase their quality (AIRS Version 5.0 Released Files Description). Specifically, total column CO data were restricted to the best retrievals (Qual_CO $=0$ ), representing values obtained primarily from the retrievals instead of values assumed a priori. The data then were simplified into normalized fields for comparison with WRF-Chem.

The lidar instrument on the Cloud-Aerosol Lidar and Infrared Satellite Observation (CALIPSO) satellite provides high vertical resolution aerosol and cloud identification within a $100 \mathrm{~m}$ across track footprint (Winker et al., 2010). 
Labonne et al. (2007) utilized CALIPSO's Cloud-Aerosol Lidar with Orthogonal Polarization (CALIOP) retrievals to represent the total emission plume by assuming that the chemical and aerosol constituents were collocated. We make this same important assumption in our research. The CALIOP sensor onboard CALIPSO provides higher resolution atmospheric profiles than most other satellite-derived products. We evaluated WRF-Chem's long range vertical accuracy using the CALIOP vertical feature mask (VFM, Vaughan et al., 2004) that provides a simplified view of a retrieval swath. To quantify WRF-Chem's forecasting skill compared to AIRS, we used the Method for ObjectBased Diagnostic Evaluation (MODE) procedure (Davis et al., 2006, 2009; http://www.dtcenter.org/met/users/). Davis et al. (2009) describe the procedure as follows. "MODE represents a class of spatial verification methods whose objective is to identify localized features of interest in scalar fields [called "objects"] and compare features in two fields to identify which features best correspond to each other. When objects have been identified and categorized, statistics of the similarities of the objects in the two datasets are computed. In this sense, MODE can be considered a rudimentary algorithm for image processing and image matching, but developed for meteorological applications. The degree of similarity between forecast and observed objects provides a measure of forecast quality". Object-based evaluation is superior to traditional point-to-point comparisons of collocated grid points because the latter can lead to double penalties if forecasts are even marginally displaced from the observations. In the current study AIRS total column CO was mapped to the same model grid as the simulated WRF-Chem total column CO. MODE then used these inputs to compute statistical skill scores for the forecast. We were conservative in our use of MODE, only comparing cases with well defined cloud free retrieval features.

\subsection{Test cases}

Six 10-day WRF-Chem simulations (28 June-8 July 2008) were run in our case study. These six runs employed the two emission preprocessing methods, Prep_chem_sources (PC) and FLAMBE (FB), and three injection height schemes: 1-D plume rise (PLR), filling the boundary layer (PBL), and releasing between $3-5 \mathrm{~km}$ a.g.l. ( $35 \mathrm{~K}$ ). Subsequent references will refer to these combinations by their abbreviations (i.e., PC_PLR, FB_35K, etc., Table 2). These three injection schemes represent a small sample of the many approaches that have been used previously (see Sect. 1).

\section{Injection height evaluation}

We evaluated the ability of WRF-Chem's 1-D plume rise configuration to produce appropriate injection heights by comparing with MISR-derived plume heights. Figure 2 is
Table 2. Configurations used during our study as defined by the biomass burning preprocessor and injection layer scheme.

\begin{tabular}{lccc}
\hline & $\begin{array}{c}\text { 1-D Plume } \\
\text { Rise }\end{array}$ & Filled PBL & $\begin{array}{c}\text { Filled 3-5 km } \\
\text { Layer }\end{array}$ \\
\hline Prep_chem_sources & PC_PLR & PC_PBL & PC_35K \\
FLAMBE & FB_PLR & FB_PBL & FB_35K \\
\hline
\end{tabular}

an example of a Canadian smoke cloud observed by MISR on 30 June 2008. Throughout the paper both the model and measurement injection heights are referenced to the geoid (not altitude above ground level). The maximum and median heights derived for this plume (Fig. 2c) represent planes that are fit to the wind-corrected heights after removing values outside of 1.5 standard deviations. We investigated whether to use the maximum or median MISR height of each plume in our comparisons with WRF-Chem. Results (not shown) indicate that using the maximum top produced a better Spearman correlation coefficient $\left(r_{\mathrm{s}}\right)$ with the WRF-Chem plumes $\left(r_{\mathrm{s}}=0.34\right)$ than did the median heights $\left(r_{\mathrm{s}}=0.11\right)$. Since this represents an ambiguity in the interpretation of the observations, we present statistics for the maximum MISR height, but comment on both the median and maximum height where appropriate.

Considering the entire ten-day simulation period, the use of FLAMBE emissions (FB_PLR) in WRF-Chem produces better agreement with MISR's maximum stereo heights than do heights from PC_PLR, e.g., a Spearman correlation of 0.45 versus 0.07 (Fig. 3). FB_PLR also simulates 54 percent of the plumes within the estimated $\pm 560 \mathrm{~m}$ error range of the MISR stereo heights (the shaded region), compared to 41 percent from PC_PLR. Several factors could lead to the observed differences between the injection heights produced by PC_PLR and FB_PLR. One factor relates to how the 1-D model in WRF-Chem parameterizes the entrainment of environmental air. Specifically, entrainment is based on an inverse relationship with plume radius, i.e., the larger the plume radius, the less inhibition that entraining cooler, unsaturated environmental air will have on the relatively warm, saturated plume. Thus, larger plumes rise to higher altitudes than smaller plumes, all other factors being equal. PC_PLR assumes a constant area of 22.8 ha for MODIS fire detections. The result is a relatively narrow range of injection heights (Fig. 3b). Conversely, FB_PLR splits the estimated 62.5 ha burn area per fire into 24 hourly segments that are proportional to diurnal fire activity (i.e., a larger burn area in the afternoon than overnight). The broader range of injection heights in Fig. 3a is associated with fire sizes ranging from 1.25 to 62.5 ha.

A related factor is that prep_chem_sources releases emissions at a constant rate during a $24 \mathrm{~h}$ period, whereas 
a)

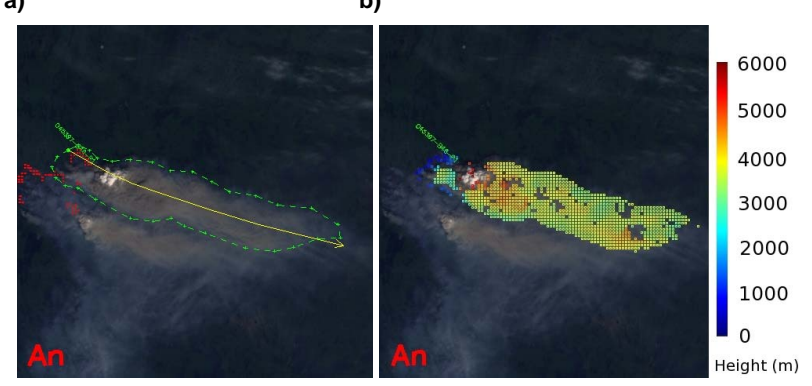

c)

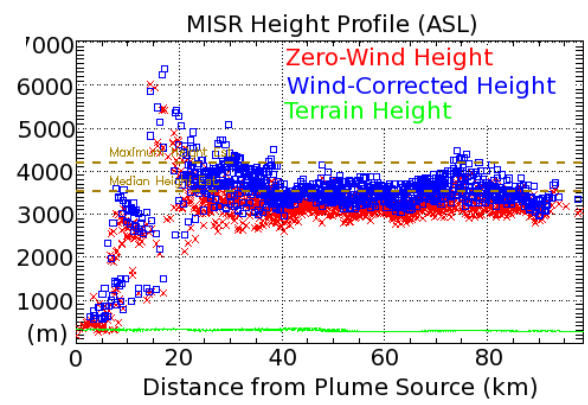

Fig. 2. Example of plume digitization produced by the MINX software package for a Canadian plume on 30 June 2008. Panel (a) shows a smoke cloud (outlined in green) with associated MODIS fire pixels (red dots). Panel (b) depicts the same plume with a stereo height overlay. The label "An" indicates that these are nadir images. (c) shows individual stereo heights within the plume in relation to their distance from the source. Planar maximum and median plume heights are shown as dashed lines. MINX images courtesy the MISR Plume Height Climatology Project (http://misr.jpl.nasa. gov/getData/accessData/MisrMinxPlumes/index.cfm).

FLAMBE includes diurnal variability by releasing 90 percent of the emissions between 09:00-19:00 LST (local standard time). Note that MISR's equator crossing time is 10:30 LST (at high latitudes the local crossing time can be different). So the improved agreement between the observed and modeled plume heights stems primarily from allowing a range of plume sizes, and since retrieval times are compared with the nearest model output time, the smaller morning burn areas in FB_PLR. Based on this more realistic portrayal of injection heights, the long-range transport simulations described in later sections will be limited to using the FLAMBE (FB) emission data.

Atmospheric stability plays an important role in simulating injection heights within WRF Chem's 1-D plume rise model (Freitas et al., 2007, 2010). Fig. 4 shows two simulated soundings over boreal plumes. Panel (a) depicts a classic subsidence inversion that creates a stable layer near $\sim 1.5 \mathrm{~km}$ a.g.l. The maximum height of the simulated injection layer of this case reaches $1.1 \mathrm{~km}$, in good agreement with the $1.3 \mathrm{~km}$ height observed by MISR. However, the injection layer is overestimated in the conditionally unstable WRF-Chem sounding in Fig. 4b. MISR observed an aerosol a)

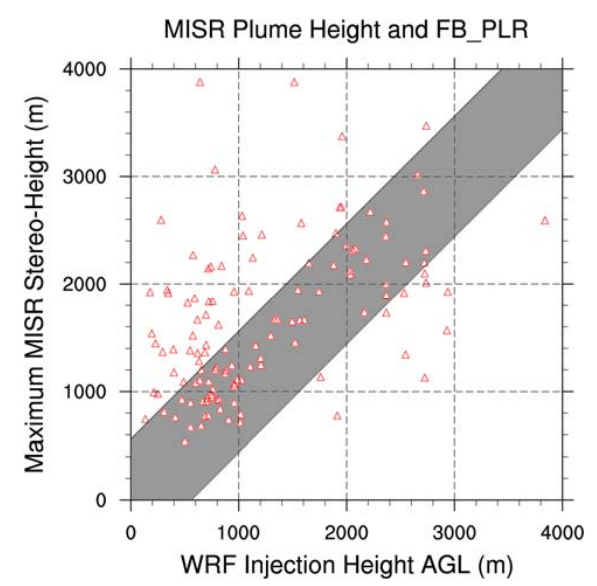

b)

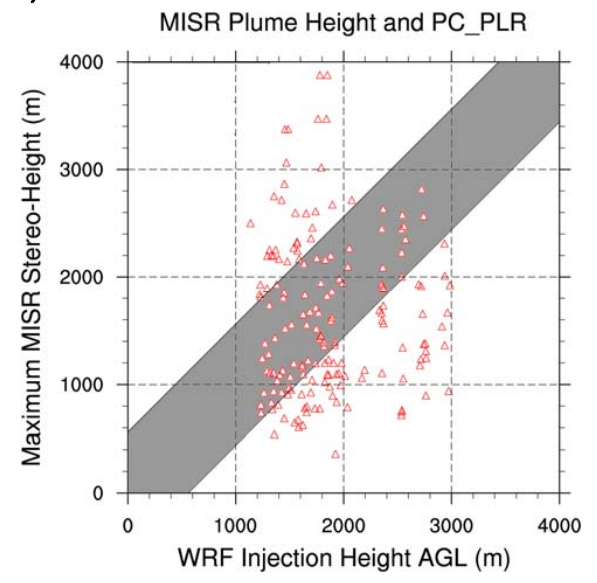

Fig. 3. Injection heights using FB_PLR plotted against MISR maximum stereo heights for the entire ten day model run. The Spearman correlation is 0.45 . (b) Same as (a), but based on PC_PLR. The Spearman correlation is 0.07 . Shaded regions represent a hypothetical perfect correlation with MISR when assuming a stereo height error of $\pm 560 \mathrm{~m}$.

layer at $2.5 \mathrm{~km}$, well below the simulated $5.4 \mathrm{~km}$ height. This suggests that the simulated sounding is less stable than the real atmosphere. Thus, limitations in the simulated stability profile can be compounded by the plume rise mechanism to produce erroneous emission layers. The important point is that accurately modeling the injection heights of atmospheric plumes requires accurately modeling the atmospheric stability structure (e.g., Kahn et al., 2007) in addition to the buoyancy and possibly other factors, such as entrainment and three-dimensional winds.

The distribution of WRF-Chem injection heights during the entire ten-day integration period (Fig. 5a, b) (not just locations matched to MISR retrievals) shows that FB_PLR produces somewhat lower injection layers than PC_PLR. Both median simulated injection heights are $\sim 2.1 \mathrm{~km}$, whereas MISR's median height is closer to $1.5 \mathrm{~km}$ (Fig. 5c). Thus, 
a)

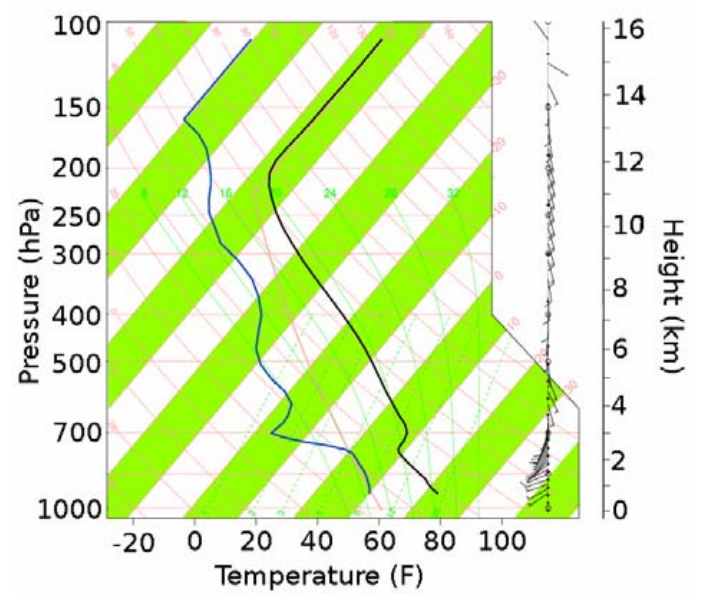

b)

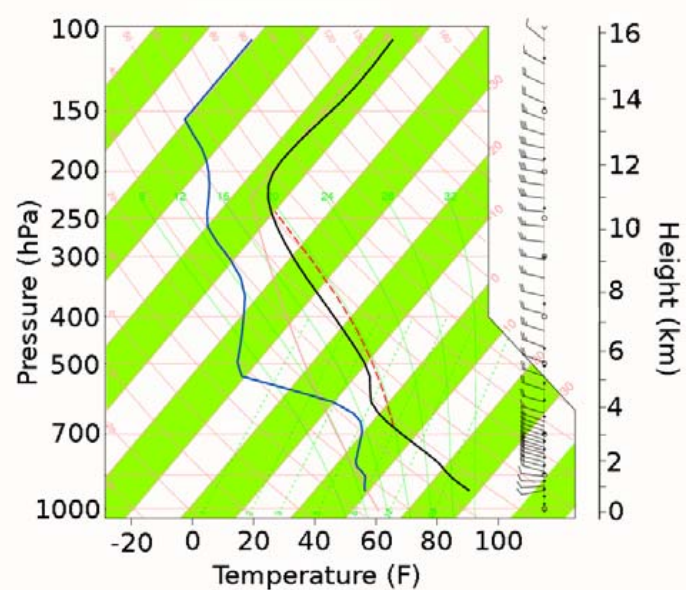

Fig. 4. Sample soundings from WRF-Chem (PC_PLR) at example locations of low $(1.1 \mathrm{~km})$ and high $(5.4 \mathrm{~km})$ injection heights. Temperature and dew point are in black and blue, respectively. Convective Available Potential Energy (CAPE) is indicated by a dashed red line.

the median simulated injection heights over the diurnal cycle are $\sim 600 \mathrm{~m}$ higher than observed by MISR in late morning. This difference is partially due to a sampling bias; the total number of observed MISR plumes is less than half the simulated plumes (Fig. 5c), all in the late morning, whereas fires modeled by WRF-Chem were obtained from Terra, Aqua (a second polar orbiting platform), as well as GOES which include afternoon events, when fires tend to be more energetic.

Extensive cloud cover over Canada prevented the satellite detection of many Canadian plumes. The Russian plumes comprise 96 percent of the MISR plumes and 87 percent of the WRF-Chem plumes during our ten day period. The observed Russian plumes average $\sim 900 \mathrm{~m}$ lower than the Canadian plumes, while the simulated Russian plumes average a)

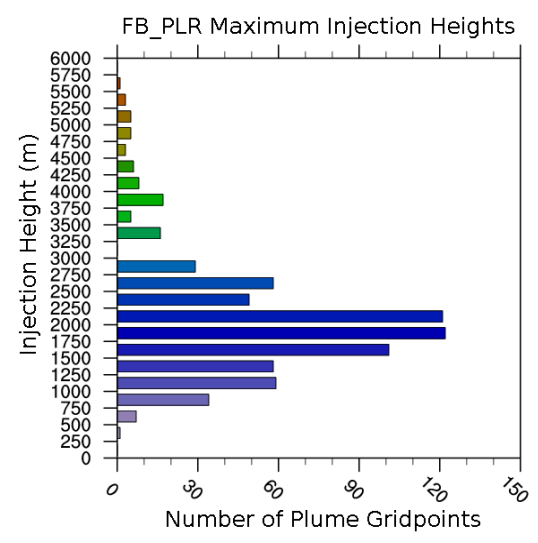

b)

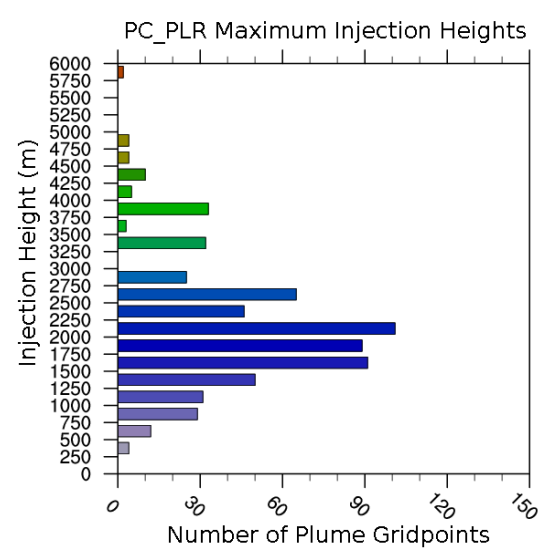

,c)

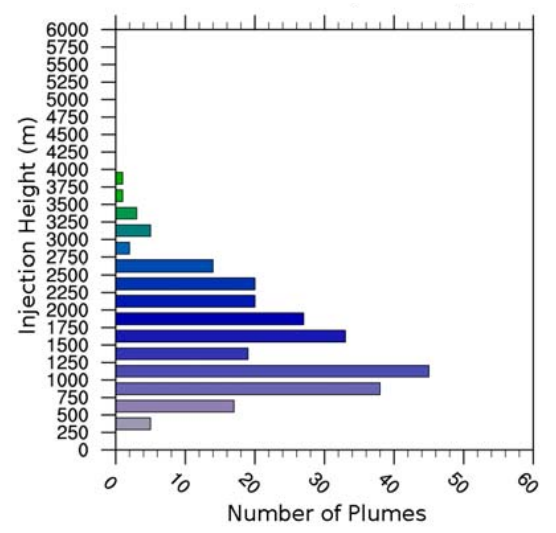

Fig. 5. Distribution of WRF-Chem maximum injection heights over Siberia and Canada during the entire ten day simulation period for (a) FB_PLR and (b) PC_PLR biomass burning emissions. (c) MISR stereo height distribution for the same period. Note the difference in scale between (c) and (a-b). 
$\sim 1.5 \mathrm{~km}$ lower than those in Canada. This greater representation (96 percent in the MISR observations versus 87 percent in the simulations) of the taller Canadian plumes in the model data produces a higher average injection height than observed by MISR.

Our first goal was to determine the amount of simulated injection that was confined to the PBL. Therefore, we matched MISR maximum plume heights to our model grid points and then compared them with the WRF-Chem PBL height at each location. Results show that most MISR-derived maximum plume heights are above the simulated PBL (Fig. 6a). Thus, if one assumes that the simulated PBL heights are reliable, there is a strong preference for injection into the free troposphere, approximately $79 \%$ of the cases in this data set. By comparison, if we had assumed median heights and considered only those plumes at least $0.5 \mathrm{~km}$ above the presumptive PBL, as done by Kahn et al. (2008) and Val Martin et al. (2010), a smaller percentage would have been injected into the free troposphere.

Our WRF-Chem simulations utilized the Yonsei University PBL parameterization that diagnoses PBL height from the buoyancy profile (Hong et al., 2006). However, the GFS diagnoses PBL heights using a bulk-Richardson number approach to iteratively estimate the height starting from the ground upward (Troen and Mahrt, 1986, Hong and Pan, 1996; http://www.emc.ncep.noaa.gov/GFS/doc.php\#pbl). To investigate the effect of using a different model with a different PBL scheme, we obtained PBL heights for the locations in Fig. 6a from archived GFS data. Results (Fig. 6b) show that the GFS-derived PBL heights are even lower and contain less variability than those from WRF-Chem (Fig. 6a). Brioude et al. (2009) also evaluated the plume rise model using GFS data, but investigated the area off the California coast. Results showed that $30 \%$ of their plumes were injected above the PBL height and that the mode of injection height matched the PBL height. Our greater amount of injection above the PBL using GFS data may be due to the different locations being studied. Brioude et al. also used a different approach to estimate the total heat flux from the fires. Their approach (MODIS FRPx10) typically returns lower heat flux values than those in Freitas et al. (2006). So, their percentage above the PBL also could be lower due to lower injection heights simulated by the model.

As a final step, we separately compared injection heights based on prep_chem_sources with those from FLAMBE (Fig. 6c) using the WRF-Chem data. The same locations were used in the comparison, only the preprocessing procedure differed. Results indicate that prep_chem-sources more often injects material above the PBL than does FLAMBE. In both the real and simulated atmospheres, there is a certain amount of fire buoyant energy that will cause a plume to overcome the real or simulated stability of the PBL and ascend into the free troposphere. The simulations suggest that the default level of fire buoyant energy used in prep_chem_sources is almost always greater than what is needed to overcome the stability of the simulated PBL, while the diurnal variation used by FLAMBE produces fire energies both above and below the critical amount.

WRF-Chem's relatively low PBL heights compared to MISR's higher plume tops are due partially to MISR's overpass time. Specifically, our comparisons in the Northern Hemisphere had to be done prior to 10:30 LST when the simulated PBL height is relatively low. However, the height of the continental PBL typically increases rapidly during the late morning. WRF-Chem's low PBL heights also may be related to the delayed heating caused by insufficient heat flux in the surface layer (Pagowski, 2004).

Some previous studies support our findings of considerable transport above the PBL, while other studies do not. Kahn et al. (2008) and Val Martin et al. (2010) compared MISR stereo heights to GEOS-4 and GEOS-5 simulated PBL heights. When using our definitions of plume height, Val Martin et al. (2010) found that between about $50-55 \%$ of MISR plume heights extended above the PBL (their Table 2). They compared 3400 plumes, while Kahn et al. (2008) compared 600 plumes (a subset of those in Val Martin et al., 2010). The original atmospheric structure data in Val Martin et al. (2010) had resolutions of $1^{\circ}$ latitude by $1.25^{\circ}$ longitude (GEOS-4) and $0.5^{\circ}$ latitude by $0.67^{\circ}$ longitude (GEOS5), with PBL heights available at $3 \mathrm{~h}$ intervals. However, a degraded resolution of $2^{\circ}$ latitude by $2.5^{\circ}$ longitude is used in the GEOS-Chem global chemical transport model. PBL heights were interpolated to the times of the MISR overpasses. Although we would expect the WRF-Chem regional simulation at $45 \mathrm{~km}$ horizontal resolution and $1 \mathrm{~h}$ temporal output to provide better resolution of the PBL than GEOS, we are not aware of any publication that has directly analyzed this issue. This subject is worthy of future investigation. In addition, some of the difference between the findings of Val Martin et al. (2010) and the current study may occur because GEOS used a different procedure for computing PBL heights than WRF-Chem. GEOS defines the PBL height as the lowest layer in which the heat diffusivity decreases to below $2 \mathrm{~m}^{2} \mathrm{~s}^{-1}$. If the heat diffusivity remains less than $2 \mathrm{~m}^{2} \mathrm{~s}^{-1}$, GEOS sets the PBL height as the surface layer (Lucchesi, 2007).

Labonne et al. (2007) found most emissions remaining in the PBL based on ECMWF data using a type of bulk Richardson number approach to determine the height of the PBL (http://www.ecmwf.int/research/ifsdocs/CY28r1/ Physics/Physics-04-09.html\#wp972354). Emissions were above the PBL only in cases of large scale lofting. However, Kahn et al. (2008) noted that Labonne et al. used only CALIOP data, making the observed heights very dependent on how far the lidar profile was from the source, and, due to the high sensitivity of the lidar observations to very thin aerosol layers, they often sampled background aerosol smoke that might not be part of major plumes. PBL heights over the ocean derived from 6 and $48 \mathrm{~h}$ forecasts from ECMWF were found to be $200-400 \mathrm{~m}$ lower than satellite-derived heights 


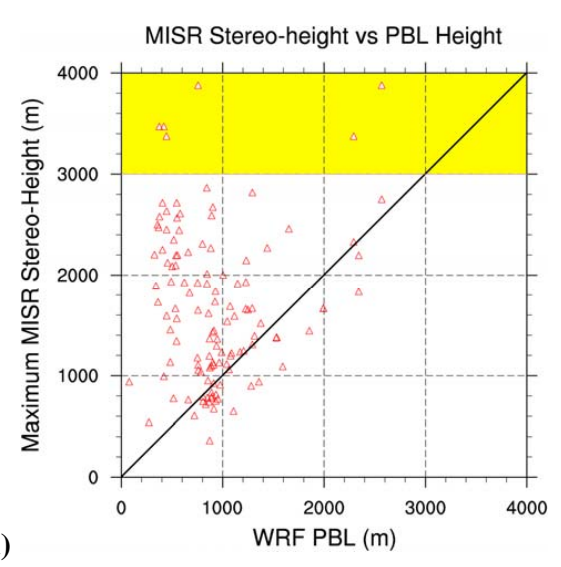

(a)

MISR Stereo-height vs PBL Height
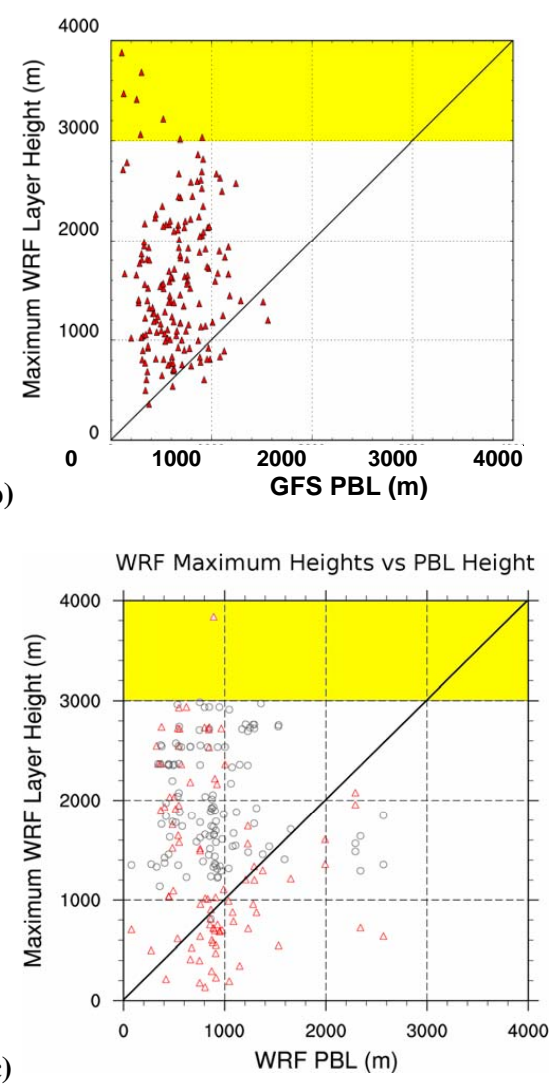

Fig. 6. (a) Maximum MISR stereo heights for ARCTAS plumes (see Fig. 2c for an example) plotted against PBL heights from WRFChem. (b) As in panel (a), but plotted against PBL heights from GFS, (c) maximum simulated injection heights for PC_PLR (black circles) and FB_PLR (red triangles) plotted against PBL heights heights from WRF-Chem. Points above the diagonal in (a) and (b) represent MISR injections above the simulated PBL. The yellow shaded region represents the lower half of the injection layer for the $35 \mathrm{~K}$ simulations. Injections occur uniformly in the $35 \mathrm{~K}$ layer; thus, the maximum injection height is at $5 \mathrm{~km}$. Injection from PLR occurs in a layer determined by the 1-D plume model. The top of this layer (the maximum height is shown in (c)).
(Palm et al., 2005). M. Val Martin (personal communication, 2011) compared MISR maximum heights with PBL heights over Siberia during ARCTAS-B period. However, she utilized PBL heights from GEOS-5 Modern Era RetrospectiveAnalysis for Research and Applications (MERRA). Her average PBL heights were $\sim 750$ higher than our results from WRF-Chem, with approximately half of the maximum MISR heights extending above the PBL, compared to considerably greater percentages from WRF (Fig. 6a) and GFS (Fig. 6b). In another study, GEOS-5 MERRA and CALIPSO PBL heights were compared over Africa and the Western Hemisphere by Jordan et al. (2010). Model-measurement correlation coefficients $(R)$ were $0.47-0.73$.

To summarize, current results show that both the FB_PLR and PC_PLR plume rise models simulate most maximum injection heights to be above the top of the PBL. This is especially true for PC_PLR (Fig. 6b), likely due to its static MODIS fire size and the resulting effect on entrainment and plume height as described previously. We believe that model resolution and the choice of the PBL scheme play important roles in comparing current results with previous findings; this currently represents an uncertainty in assessing the fraction of plumes injected above the PBL. We do not know of any published study that has evaluated results from various model resolutions and numerical PBL options against actual observations. Such a study would be very useful in deciding which PBL methodology to use in a CTM. Although current results indicate that most emissions escape the simulated PBL, further testing at other times and locations is needed to verify the current case study results from the 10 day ARCTAS period. However, based solely on the Russian and Canadian plumes in our study, limiting injections to the PBL does not appear to be an optimum parameterization.

Some previous studies have injected emissions in the 3$5 \mathrm{~km}$ layer, between $0-3 \mathrm{~km}$, and between $0-5 \mathrm{~km}$. However, current results for the $3-5 \mathrm{~km}$ layer show that this alternative agrees poorly with observed heights (Fig. 6). The triangular area above the diagonal but below the yellow shading represents the most common injection layer, above the PBL but below $3 \mathrm{~km}$. Thus, very few of the matched plumes are injected above $3 \mathrm{~km}$ during the ARCTAS period. Once again, additional evaluations in other areas and during other meteorological conditions are needed to confirm these results. An alternative to injection in fixed layers or using an embedded plume model would be to use homogeneous injection in a layer $\pm 1 \mathrm{~km}$ relative to the PBL height. This $\pm 1 \mathrm{~km}$ layer is approximately the width found in Fig. 7 of Val Martin et al. (2010). 


\section{Long range transport}

Since wind direction and speed vary with altitude, differing injection heights will influence the direction and speed of long range plume transport. This important aspect of modeling chemical transport is described next. Before doing so, however, it is important to examine meteorological conditions during the 10 day simulation period.

\subsection{Meteorological conditions}

Flow patterns during the summer phase of ARCTAS mostly were within climatological norms, except that a quasistationary polar low was displaced toward northern Russia, thereby enhancing transport into the Arctic (Fuelberg et al., 2010). The counterclockwise winds around the displaced quasi-stationary polar low (Fig. 7a, b; Fuelberg et al., 2010) provides one of two primary transport pathways off the Asian continent during our integration period (28 June8 July 2008). The northern path toward the Arctic begins over the Chukotski Peninsula, located on the opposite side of the Bering Strait from Alaska. The southern path transports Asian pollutants eastward. It is created by an exiting midlatitude cyclone southeast of the Kamchatka Peninsula. Once this cyclone moves offshore, high pressure over the Stanovoy Range clears the sky, dries the surface, and promotes the fire activity whose plumes are examined in the following sections. The stream bifurcation between these two paths begins at the saddle point between the two low pressure systems, and is most clearly visible in the $850 \mathrm{hPa}$ streamline analysis on 29 June (arrow in Fig. 7a). However, the northern pathway does not fully form until the saddle point degrades on 6 July (Fig. 7c). A mid-latitude cyclone approaches the Aleutian archipelago on 2 July before merging with the Aleutian low on 6-8 July.

The fires in Canada and Alaska were ignited by lightning from a succession of cyclonic storms beginning with a shortwave trough on 28 June that passes over Saskatchewan (Fig. 7e-h). This cyclone is followed by a second system that also initiates thunderstorms, including a pyroconvective cell on 29 June in the Northwest Territories (M. Fromm, personal communication, 2009). The flow downwind of the Canadian fires is dominated by two semi-permanent lows located over Ontario/Quebec and southeast of Greenland, respectively. This combination produces a transport pathway toward the North Atlantic Ocean that limits transport into the Arctic.

\subsection{AIRS - derived observed transport}

AIRS-derived CO serves as our standard for comparison with the WRF-Chem simulations. The AIRS Level 3 total column CO product (Fig. 8) exhibits several distinctive features during the 10 day simulation period. Although a potential low bias in the data over northern latitudes and the sensor's weak sensitivity in the surface layers may prevent accurate measurement in some regions (J. Warner, personal communication, 2010; Fisher et al., 2010), general CO patterns still can be deduced. A large CO plume is located over Russia and China on 28 June with extensions over the Pacific Ocean (Fig. 8a). This Russian plume was evident during the week prior to our integration period (not shown) as a combination of smaller plumes over the region, together with another plume farther south over China. These plumes formed prior to our study period and were not part of the initial conditions.

Beginning on 2 July (Fig. 8c), the dominant transport pathway from Russia extends over the Sea of Okhotsk northward over the Kamchatka Peninsula. The bulk of the plume flows eastward over the northern Pacific Ocean, but small CO concentrations are located north of the Chukotski Peninsula. By 6 July (Fig. 8e), flow around the quasi-stationary polar low begins to advect larger concentrations of $\mathrm{CO}$ northward toward the Bering Strait and the Arctic (the arrow in Fig. 8e). This panel clearly displays the two transport routes mentioned earlier. On 8 July (Fig. 8f), the CO plume diffuses across the Pacific; however, partial cloud cover prevents retrievals in the Arctic north of Canada and Greenland.

The Canadian CO plumes are much smaller and weaker than those from Russia, and they exhibit a simple path toward the Atlantic Ocean. Their CO signal can be seen early during the study period spreading from central Canada to south of Hudson and James Bays (Fig. 8b). CO first is transported east-south-eastward across the central provinces. Flow around the low pressure systems keeps the plumes south of Hudson Bay and Greenland before transport over the North Atlantic (Fig. 8e). The influence of fires in California and the previously described Russian plume also can be seen on 6-8 July (Fig. 8e, f).

\subsection{Simulated Russian transport}

We next compare plumes from the three FLAMBE model configurations with each other and with remotely sensed imagery. Recall that the three injection procedures were: in the PBL (FB_PBL), using the 1-D plume model (FB_PLR), and between 3 and $5 \mathrm{~km}$ above ground level (FB_35K). Except for these different injections, all other aspects of the model configuration were identical. The comparison is done both qualitatively (with CALIOP and AIRS) and quantitatively (with AIRS). One should recall that we assume that the CO and aerosols comprising the plumes are collocated. Plumes from Russia are examined first.

Figure 9a shows injection heights for plumes originating over Russia (a subset of the locations in Fig. 6b). The three injection procedures produce very different altitudes. Injections in the PBL generally are closest to the surface; the 1-D plume model generally injects the plumes at higher altitudes; and injection between $3-5 \mathrm{~km}$ occurs at the highest altitudes. Since wind direction and speed almost always vary between the surface and $5 \mathrm{~km}$, the transport of these plumes will be 

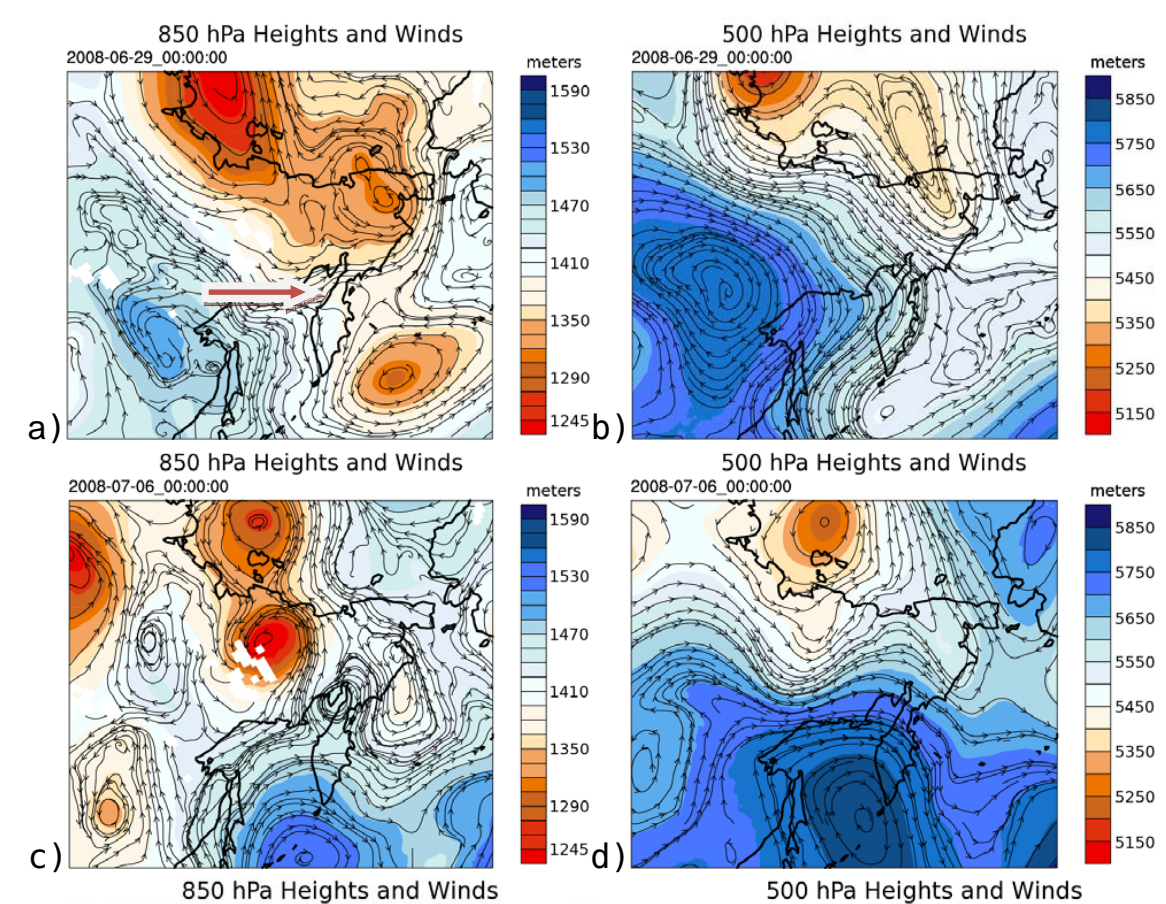

c)

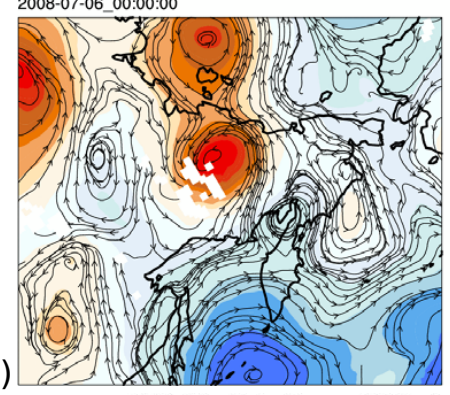

$850 \mathrm{hPa}$ Heights and Winds
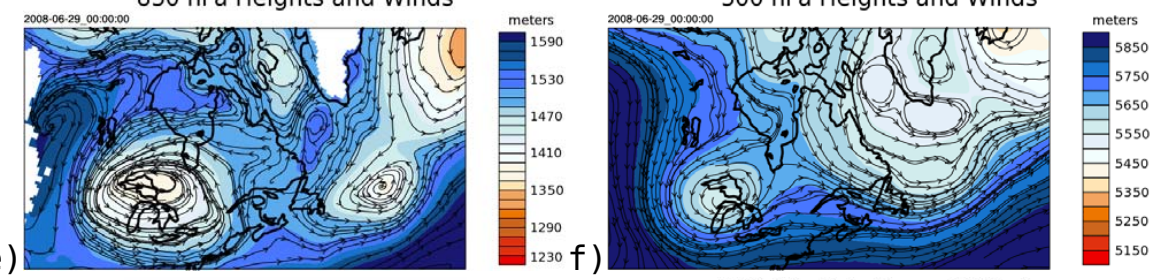

$500 \mathrm{hPa}$ Heights and Winds
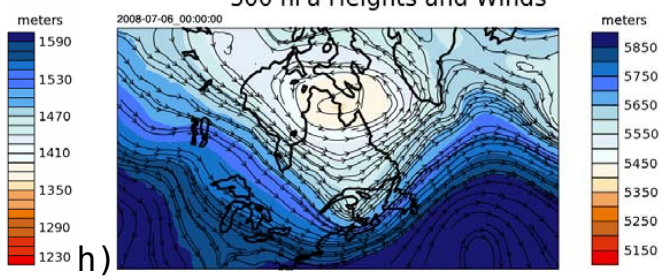

Fig. 7. Geopotential heights (color filled lines) and streamlines over northeastern Asia and the North Pacific Ocean and North America at $850 \mathrm{hPa}$ and 500 hPa for 00:00 UTC 29 June and 00:00 UTC 6 July 2008. The arrow in (a) denotes the saddle point where the north and south pathways from Russia split. Note that streamlines and trajectories are not equivalent.

affected. The three procedures for injecting biomass emissions (FB_PLR, FB_PBL, FB_35K) produce similarly shaped plumes on 2 July (4 days into the simulation, Fig. 10a, c, e), with flow over the Sea of Okhotsk and subsequent branching southward and northward. This similarity indicates that the simulated low-level winds vary little with height in the vicinity of the plumes. The branches are similar to those observed in the AIRS CO data (Fig. 8c) except that the simulated plumes are located slightly farther northwest, not over the southern tip of the Kamchatka Peninsula. On 5 July (not shown), FB_PBL's plume over the Chukotski Peninsula moves southeastward, and by 6 July (7 days into the simulation, Fig. 10f) forms a branch into the Arctic near the Date Line. In contrast, plumes from FB_PLR and FB_35K are stretched northward, west of FB_PLR, by 6 July (Fig. 10b, d). AIRS detects a region of enhanced $\mathrm{CO}$ stretching from the Chukotski Peninsula to the Bering Strait (Fig. 8e), agreeing best with FB_PLR and FB_35K. These differences in plume locations (Figs. 8, 10) occur because plumes based on FB_PLR and FB_35K are transported northward, mostly above the PBL. Conversely, the plume from FB_PBL takes a more eastbound course since the lower level flow in which the injection occurs are more westerly.

Vertical cross sections along the CALIPSO track (Fig. 11) allow plume altitudes to be compared. The 00:34 UTC 6 July ascending CALIPSO overpass (Fig. 11a) crosses the dateline near $30^{\circ} \mathrm{N}$, heading northwest over the Chukotski Peninsula. This track passes over the northbound plume arch in Fig. 10b, 
a)

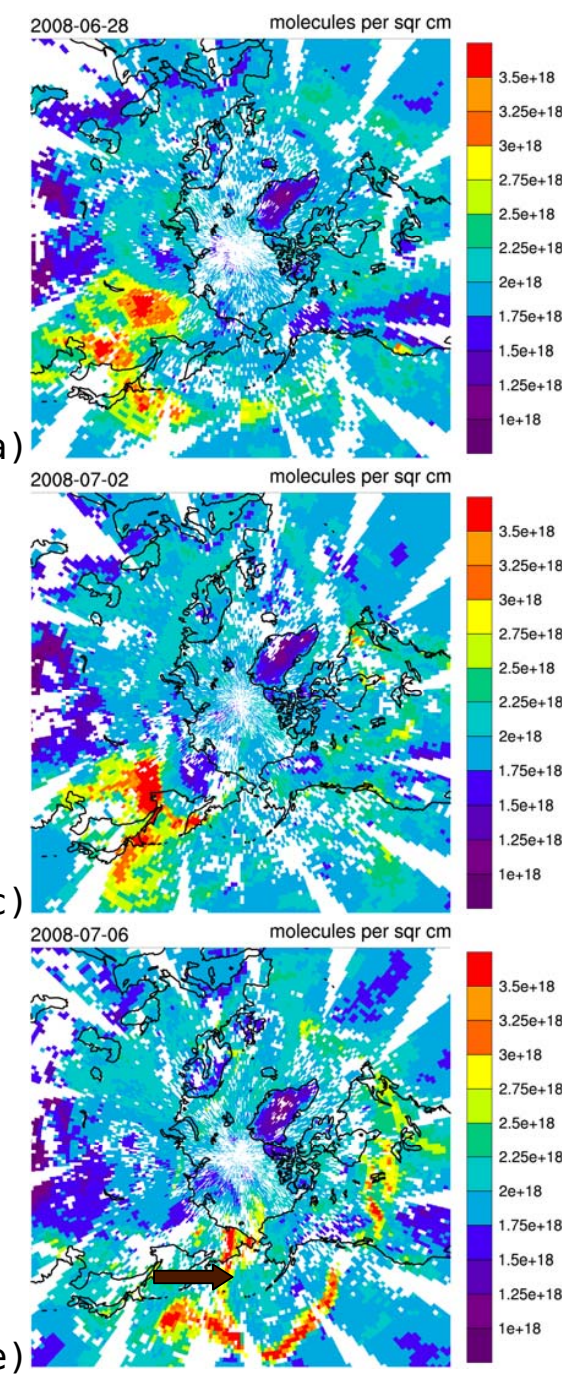

b)

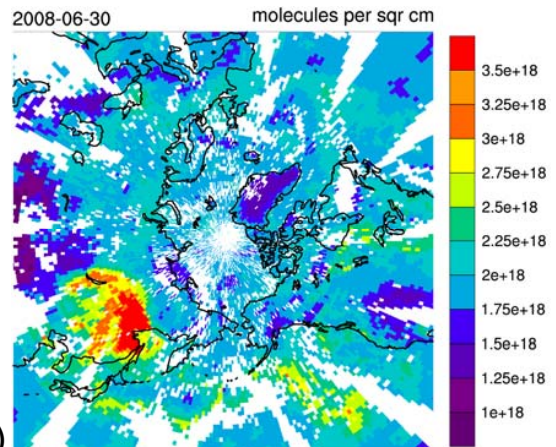

d)
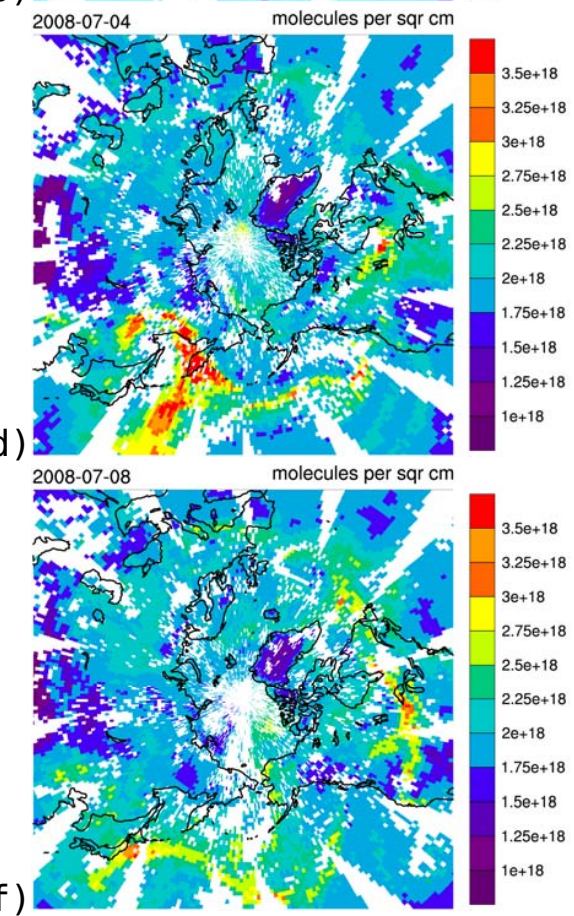

Fig. 8. AIRS $1 \times 1$ deg Level 3 Total Column CO (molecules $\mathrm{cm}^{-2}$ ) between 28 June- 8 July 2008 . The arrow in (e) is the second plume discussed in the Arctic long range transport section.

$\mathrm{d}$ and the FB_PBL plume over the North Pacific Ocean. The cross sections from FB_PLR and FB_35K (Fig. 11b, d) exhibit similarities, with the core of the Arctic-bound plume lofted to between 3-7 km. FB_PLR and FB_35K exhibit especially strong concentrations between $\sim 4-7 \mathrm{~km}$ (Fig. 11b, d). The FB_PBL plume (Fig. 11e) is advected northeast at a much lower altitude $(\sim 2 \mathrm{~km})$ than the other two plumes.

All three simulations place a small pocket of aerosols at differing altitudes at the southern (left) edge of the cross sections near $43^{\circ} \mathrm{N}$ (Fig. 11b, d, e). Although the CALIOP Vertical Feature Mask (VFM, Fig. 11c, Vaughan et al., 2004) shows an aerosol (orange) layer near $48^{\circ} \mathrm{N}$, it is embedded in clouds and is not considered reliable. However, the VFM also indicates an aerosol layer at $\sim 9 \mathrm{~km}$ altitude farther north near $60^{\circ} \mathrm{N}, 175^{\circ} \mathrm{W}$ that does not appear to be cloud contaminated. This altitude agrees best with those from FB_PLR and FB_35K (Fig. 11b, d). Unfortunately, the
VFM shows frontally induced clouds (light blue) even farther north (right) where the simulated plumes from PLR and $35 \mathrm{~K}$ are strongest. Frontally related cloud formations such as this often contain enhanced emissions (Crawford et al., 2003); however, the clouds frequently limit their remote detection using infrared techniques, and also can affect the properties and removal rate for the smoke itself. One should note, however, that the presence of the FB_PLR and FB_35K plumes over the Chukotski peninsula is corroborated in the AIRS CO data (Fig. 8e).

AIRS total column CO data on 2 and 6 July (Fig. 10) are used to quantitatively compare $\mathrm{CO}$ structures from the three WRF-Chem configurations. Although MODE's object-based evaluation (Sect. 2.2) produces several statistical measures, we focus on the critical success index (CSI) whose values range from 0 (no skill) to 1 (perfect agreement). One should note that MODE scores are limited by the quality of the AIRS 
a)

WRF FB_PLR, FB_35K, FB_PBL vs PBL Height - Russia

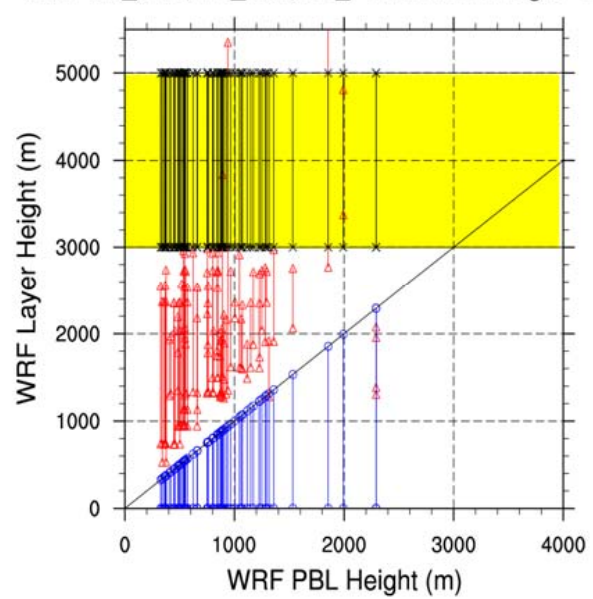

b)

WRF FB_PLR, FB_35K, FB_PBL vs PBL Height - Canada

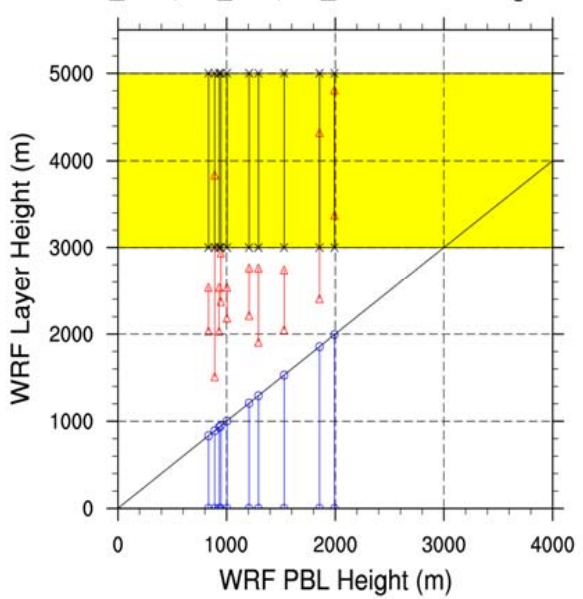

Fig. 9. Simulated injection heights for FB_PLR (red triangles) and FB_PBL (blue circles), and FB_35K (black crosses) plotted against simulated PBL heights from WRF-Chem for (a) injections in Russia and (b) injections in Canada. The yellow shaded region represents the injection layer for the $35 \mathrm{~K}$ simulations. Since the emissions were not released at a single altitude, the various vertical lines represent the layer over which injection occurred.

data. Although we insured that areas masked by clouds in the AIRS data also were masked in the model fields, even this procedure can either hurt or help a MODE-derived score depending on the accuracy of the region that is removed. For example, if WRF-Chem overestimates a plume that is located in a region where clouds mask the AIRS retrievals, when the overestimated region is removed, the score is spuriously increased. Nonetheless, we consider the MODE procedure to be superior to schemes that compare grid points instead of objects.
CSI scores for the Russian plume on 2 July, four days into the simulation, are FB_PLR (0.52), FB_35K (0.49), and FB_PBL (0.42). Thus, the 1-D injection procedure scores better than the other two schemes, although the difference between the first two scores probably is not significant. CSI scores four days later (6 July, day 8) are FB_PLR (0.71), FB_35K (0.67), and FP_PBL (0.41). The values for PLR and $35 \mathrm{~K}$ have increased considerably while the score for PBL decreased slightly. The 1-D injection approach continues to produce the best agreement with the AIRS retrievals. The smaller scores on 2 July than 6 July likely are influenced by emissions in the AIRS data that originated before our modeling period began. FB_PBL's relatively low score on 6 July (0.41) probably is due to under representing the emissions over the northern Chukotski Peninsula. The spreading of the simulated plumes into China (Fig. 9) could not be evaluated since the region is largely masked by clouds in the AIRS product (Fig. 8e).

\subsection{Simulated Arctic transport}

The previous section noted that the major Russian plume splits into northbound and southbound components (Fig. 10). We now describe the northbound plume as it moves into the Arctic. The location of the plume with respect to the overall Russian plume is shown by the arrow in Fig. 10b, while details are in Fig. 12. On 3 July (five days into the simulation, Fig. 12a, c, e), all three injection procedures produce a $\mathrm{CO}$ intrusion between 160 and $180^{\circ} \mathrm{E}$. On the following day (not shown), the three versions of plumes reach the North Pole. These locations correspond to weak AIRS CO enhancements in the area (Fig. 8d). The plumes then move slowly across the pole toward northern Norway on 6 July (not shown).

The three model plumes differ in size and orientation (Fig. 12) because they have experienced different flow patterns since being injected at different altitudes (Fig. 9). The plume based on injection between $3-5 \mathrm{~km}$ (Fig. 12c) is the largest of the three on 3 July, while 1-D injection (Fig. 12a) yields the smallest plume. One should note that the emissions from FB_PBL and FB_35K exhibit an anticyclonic hook near the date line (Fig. 12c, e) that is not observed with FB-PLR (Fig. 12a). This occurs because the CO from PLR and 35K is lofted earlier into the mid- and upper-troposphere than is PLR. All three plumes enter the Arctic at similar altitudes ( $\sim 6 \mathrm{~km}$, Fig. 13b, d, e), and have similar values along CALIPSO's path. Unfortunately, the light blue region in the CALIOP VFM (code 2) indicates that the area of the plume is shrouded with clouds. Thus, we cannot verify the altitudes of the simulated plumes with CALIOP's observations.

Synoptic analyses (e.g., Fig. 7) indicate that the Arctic transport event is due to a warm conveyor belt (WCB) associated with a wave cyclone over extreme northern Russia. The WCB transports Russian pollution northward and to higher altitudes in advance of the surface cold front. The role of middle latitude cyclones on pollution transport has been 

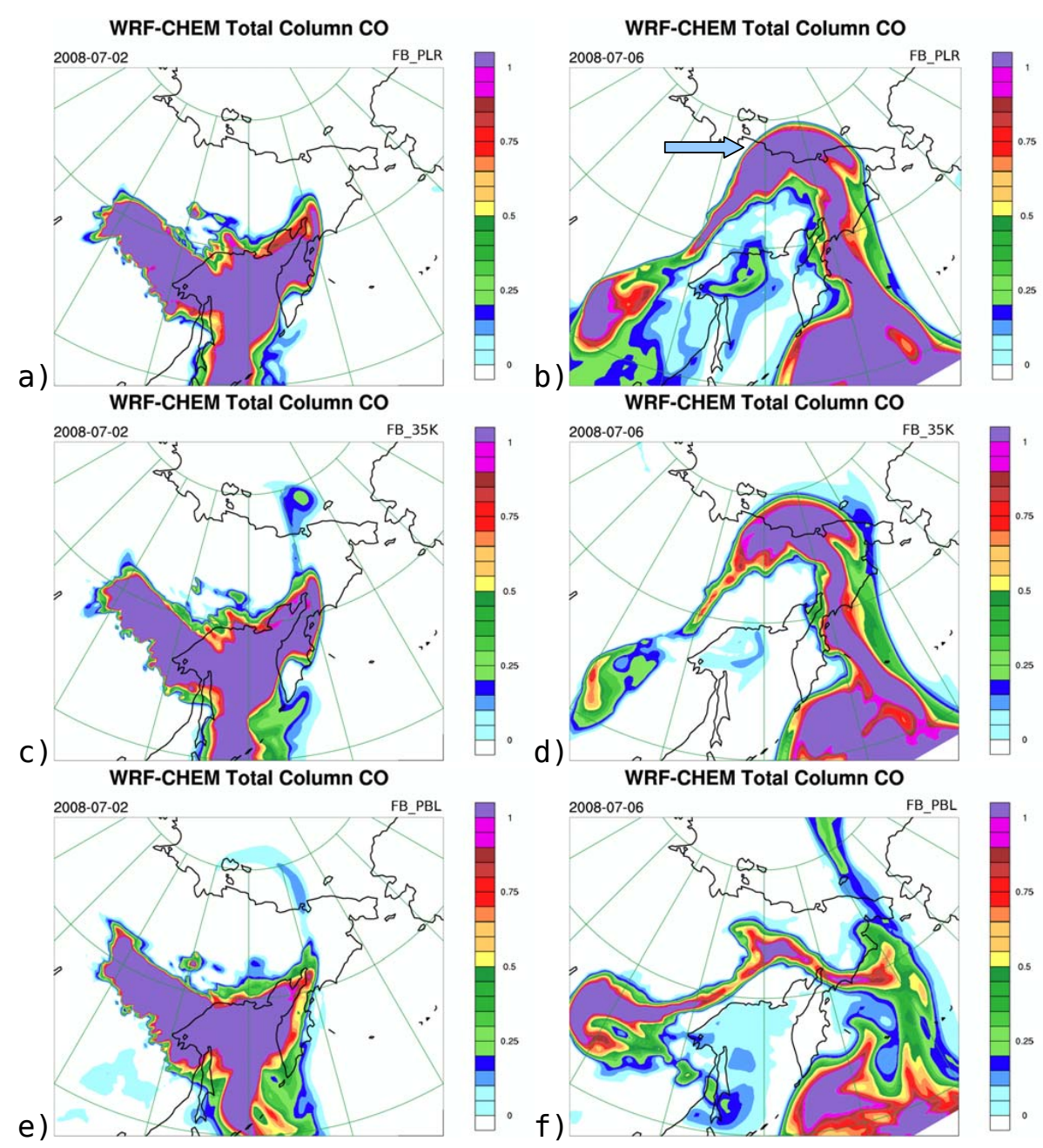

Fig. 10. Normalized WRF-Chem Total Column CO for the Russian plume over Asia and the western Pacific Ocean for (a, b) FB_PLR, (c, d) FB_35K, and (e, f) FB_PBL for (a, c, d) 2 July and (b, d, e) 6 July 2008. The arrow in (b) denotes one of the plumes discussed in the Arctic transport section.

studied extensively (e.g., Jaffe et al., 1999, 2003; Cooper et al., 2004; Liang et al., 2004; Dickerson et al., 2007). Climatological trajectory analyses have shown that northeastern China and Russia have a large frequency of WCB events (Eckhardt et al., 2004; Stohl, 2001). WCBs have been found to be a dominant mechanism in vertically redistributing pollution in the middle latitudes (Bethan et al., 1998; Wild and Akimoto, 2001; Miyazki et al., 2003; Kiley and Fuelberg, 2006). Ding et al. (2009) examined a plume that originated near the megacities of Beijing and Tianjin during Summer 2007. They concluded that a WCB played a major role in exporting the plume to the Arctic and North America. Their study period appears very similar to the current ARCTAS case.

An even more interesting second Arctic transport event occurs during the final two days of the ten day simulation period (7-8 July) when a different portion of the overall Russian plume "breaks off" and heads toward the Arctic. A
WCB associated with a later middle latitude cyclone over northeastern Russia again is the cause for the northward intrusion. The location of the Arctic bound plume on 6 July is depicted by the arrow in the AIRS CO image (Fig. 8e). By 8 July (Fig. 12b, d, f), the three simulated plumes have reached the western hemispheric portion of the Arctic Ocean and southward along the Bering Strait. Plumes resulting from FB_PLR and FB_35K injection exhibit some horizontal similarity (Fig. 12b, d), with both oriented along coastal Alaska and approaching Canada's Queen Elizabeth Islands. However, the overall horizontal extent of the $35 \mathrm{~K}$ plume is much greater than its PLR counterpart, as is the area of greatest concentrations. The vertical distributions of these two simulated plumes are similar (Fig. 14b, d) in that they generally are oriented along the sloping isentropic surfaces.

PBL injection (FB_PB) produces a plume that is very different from those of the other two injections (Fig. 12f). These major differences are seen in the plume's location, shape, and 
a)

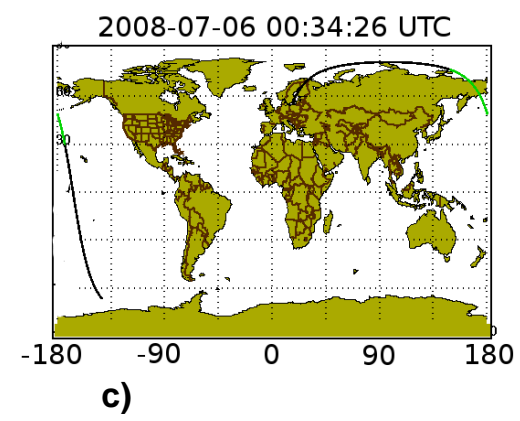

c)

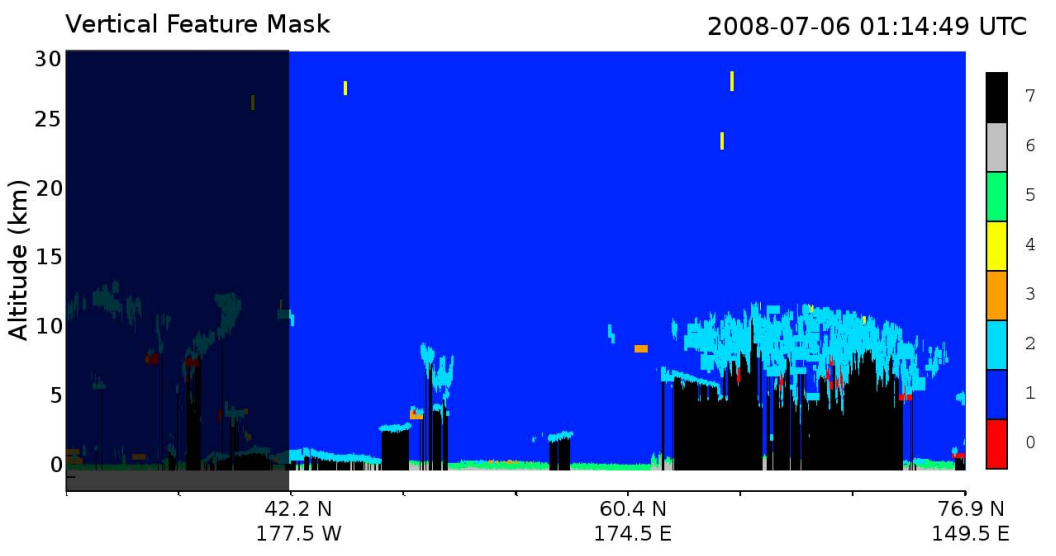

$0=$ low $/$ no confidence, 1 = clear air, $2=$ cloud, 3 = aerosol,

4 = stratospheric feature, 5 = surface, 6 = subsurface, 7 = no signal

d)

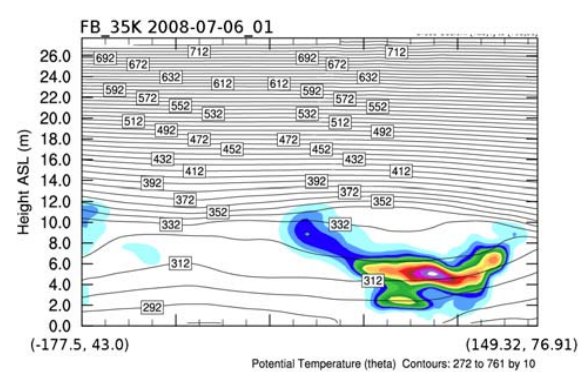

b)

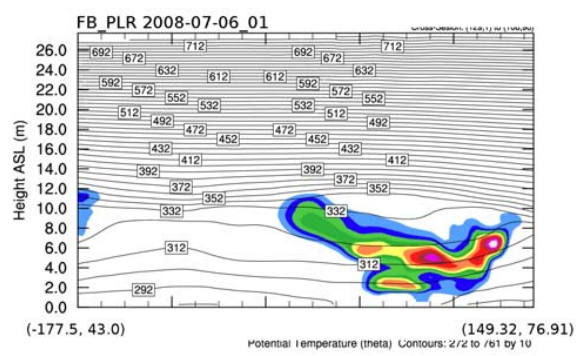

2008-07-06 01:14:49 UTC

e)

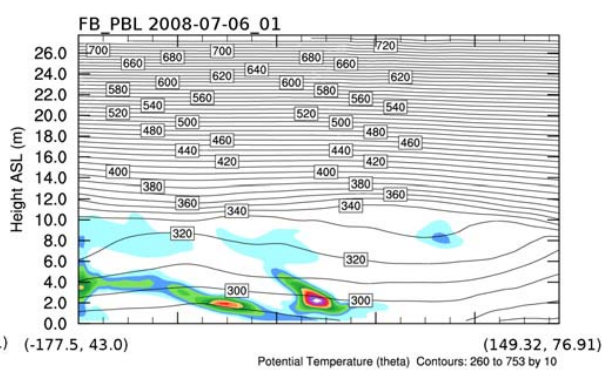

Fig. 11. (a) Map of CALIPSO path at 00:34 UTC 6 July 2008 with the analyzed segment over Russia in green and (c) the CALIOP vertical feature mask (VFM). Normalized WRF aerosol plumes for (b) FB_PLR, d) FB_35K, and (e) FB_PBL along the CALIPSO track. The left side of each cross section is the south eastern starting point, while the right side is the north western ending point.

total column CO concentration. FB_PBL's emissions reach the Arctic earlier than those from the other runs, producing enhanced transport toward Europe and weaker emission loading near North America. One should recall that PBL injection occurs at lower altitudes than the other procedures (Fig. 9a). The different wind directions and speeds at the locations and altitudes of injection send the plume material in somewhat different directions (both horizontally and vertically), and these differences accumulate during the 8 day integration period to produce the contrasts seen in Fig. 12f. Thus, in some meteorological conditions small differences in plume location or concentration early in a simulation can lead to much greater differences later in the simulation due to the accumulation process. These differences in horizontal placement appear in the vertical cross section (Fig. 14).

Cloud cover severely limits investigation of the second Arctic plume using CALIOP data from the 19:25 UTC 7 July polar overpass (Fig. 14c) and prevents meaningful quantitative comparisons of the simulated plumes using MODE. The two arrows on the VFM denote locations of the FB_PLR and FB_35K plumes in Fig. 14b, d. These regions either are shrouded in clouds (light blue), exhibit low confidence (red), or meet the criteria for being stratospheric (yellow). We have little confidence in the single pixel at location 2 that is 
a)
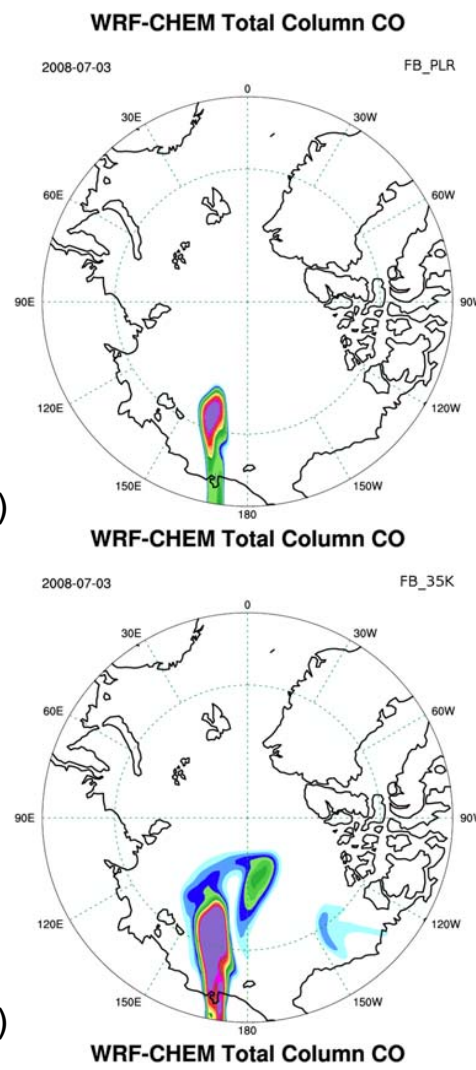

C)

$$
\text { WRF-CHEM Total Column CO }
$$

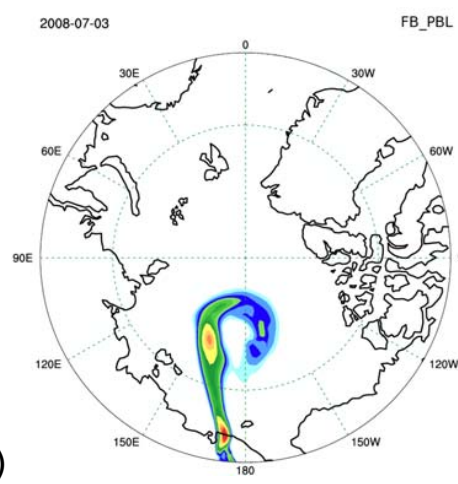

WRF-CHEM Total Column CO
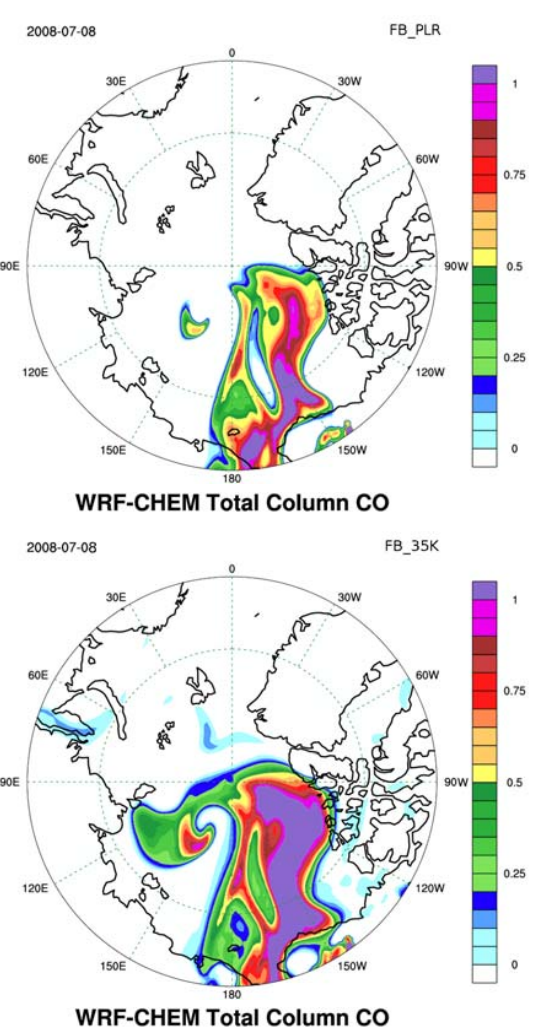

FB_PBL

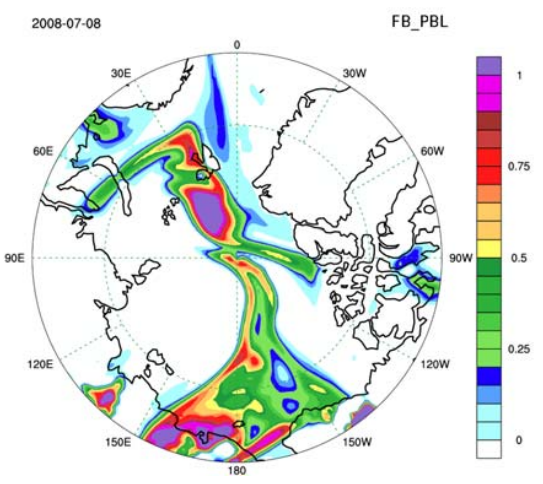

Fig. 12. Normalized WRF-Chem Total Column CO for two northern branches of the Russian plume over the Arctic Ocean for (a, b) FB_PLR, (c, d) FB_35K, and (e, f) FB_PBL on (a, c, d) 4 July and (b, d, e) 8 July 2008.

denoted aerosol (orange) since it is embedded in the clouds. These clouds detected by CALIOP correspond to a gap in the AIRS CO field on 8 July (Fig. 8f). We noted earlier that frontally related cloud features such as WCBs often coincide with important chemical plumes (Crawford et al, 2003), and that certainly is the case here. The simulated winds associated with FB_PBL's early entrance into the Arctic (Fig. 12f) steer much of the plume away from North America. If this simulated plume location were correct, CALIPSO would not have observed it due to the satellite's path (Fig. 14a).

\subsection{Simulated transport from Canada}

Our final example is a plume emitted by the Canadian wildfires. Figure $9 \mathrm{~b}$ shows injection heights for plumes originating over Canada (a subset of the locations in Fig. 6b). The three injection procedures again produce very different altitudes. Similar to results of the Russian plumes (Fig. 9a), the Canadian injections in the PBL are closest to the surface, extending only to $2 \mathrm{~km}$ a.g.l.; the 1-D plume model injects the plumes at higher altitudes; and injection between $3-5 \mathrm{~km}$ occurs at the highest altitudes. Some injection heights from the 1-D plume rise model extend into the $3-5 \mathrm{~km}$ layer. 
a)

c)
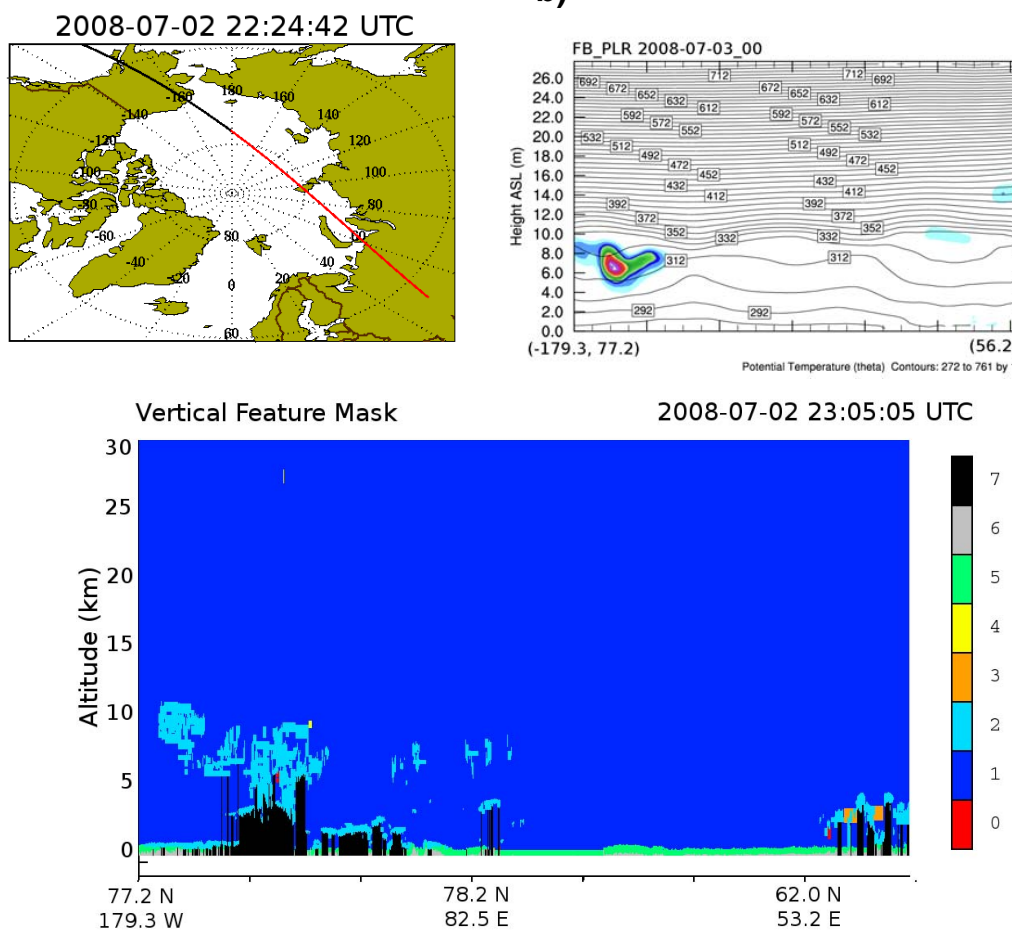

$0=$ low $/$ no confidence, 1 = clear air, 2 = cloud, 3 = aerosol,

$4=$ stratospheric feature, 5 = surface, $6=$ subsurface, $7=$ no signal

d)

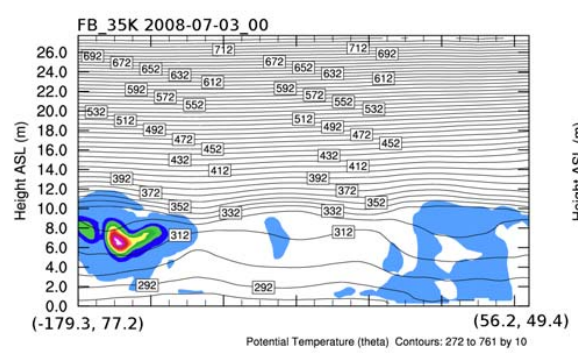

b)

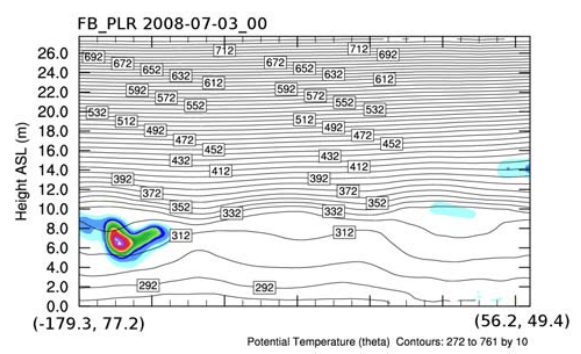

e)

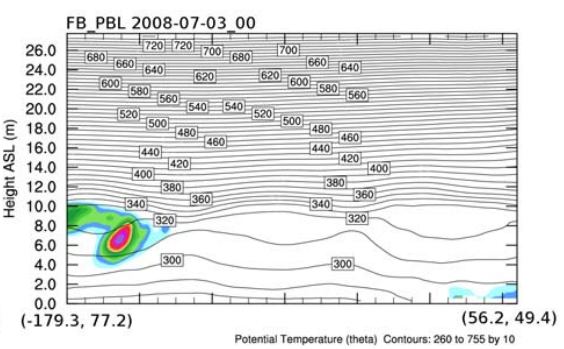

Fig. 13. (a) Map of CALIPSO path at 2224 UTC 2 July 2008 with analyzed segment near the North Pole in red and (c) the CALIOP vertical feature mask (VFM). Normalized WRF aerosol plumes for (b) FB_PLR, d) FB_35K, and (e) FB_PBL along the CALIPSO track.

Results show that the three injection procedures have little effect on the location or altitude of the resulting plumes. This similarity again is due to weak vertical wind shear in the lower troposphere.

Emissions from fires between Great Slave Lake and Reindeer Lake first move toward the south due to northerly winds and then eastward across Lake Winnipeg. The mid-latitude cyclone responsible for the southward transport moves east by 6 July (Fig. 7h), producing westerly flow that transports the plume farther east. The locations and areas of the plumes on 2 July (Fig. 15a, c, e) are similar, whether due to injection by the 1-D plume model, within the PBL, or between 3-5 km. Time series (not shown) reveal that the weaker simulated concentrations connecting the Canadian plume to James Bay (best seen in Fig. 15b) are due to emissions from the more distant Alaskan wildfires. Although this region contains little
AIRS data because of clouds, a $\mathrm{CO}$ enhancement is evident over James Bay (Fig. 8c). After 2 July, emissions from each injection procedure are transported rapidly over the warm sector of the passing cyclone where they are lofted to similar transport altitudes. The plumes then pass over central Canada (not shown) at altitudes between $\sim 3.0-3.8 \mathrm{~km}$ before moving over the North Atlantic. Once the three versions of the simulated Canadian fire plume are over the Atlantic on 7 July (Fig. 15b, d, e), each splits, with part transported northward toward Greenland by a closed low over Hudson Bay, while the major portion continues eastward. The split region of $\mathrm{CO}$ just south of Greenland is evident in the AIRS imagery (Fig. 8f). The bifurcation is similar to the branching seen in the Russian plume over the Sea of Okhotsk (left panels of Fig. 10). However unlike the Russian plume, the northern branch of the Canadian plume does not fully develop 
a)

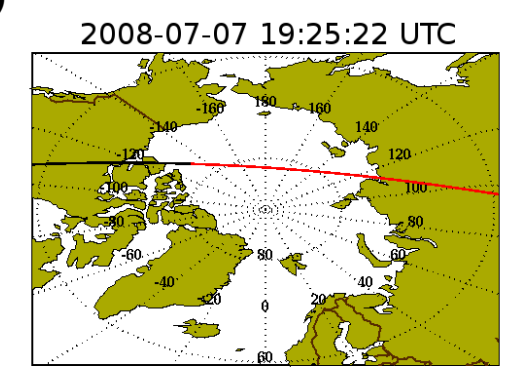

b)

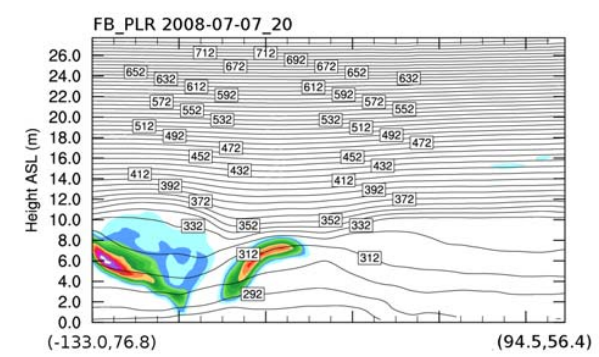

c)

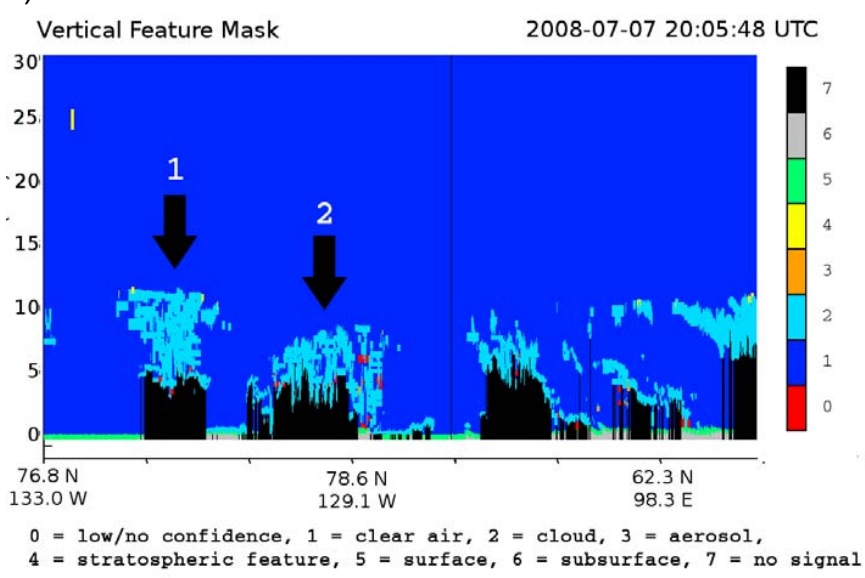

d)

e)
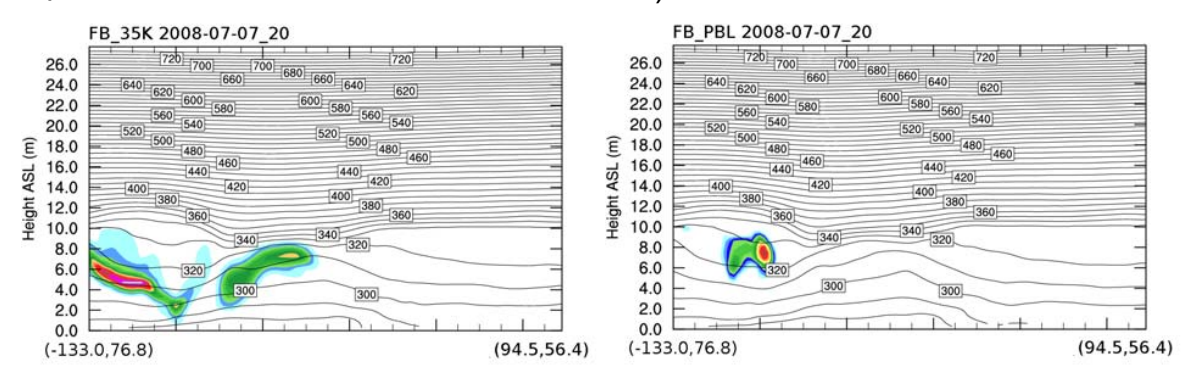

Fig. 14. (a) Map of CALIPSO path at 19:25 UTC 7 July 2008 with analyzed segment near the North Pole in red and (c) the CALIOP vertical feature mask (VFM). Normalized WRF aerosol plumes for (b) FB_PLR, (d) FB_35K, and (e) FB_PBL along the CALIPSO track. Arrows in (c) represent features described in the text.

and does not reach the Arctic. The relatively small Arctic plume seen on 6 June (Fig. 10c) crossed over the North Pole (not shown) and now is located between Iceland and the United Kingdom (Fig. 15d). It is unique to the higher altitude FB_35K simulation.

The three cross sections of normalized $\mathrm{CO}$ along the CALIOP track also are very similar (Fig. 16b, d, f). Each type of injection produces an area of enhanced $\mathrm{CO}$ along the northern (right) side of the track that is centered near $6 \mathrm{~km}$ altitude. These areas slope downward in the southerly (left) direction. Each cross section also exhibits a second, weaker area of enhancement farther south between $\sim 6-10 \mathrm{~km}$ altitude.
The two arrows on the CALIOP VFM product (Fig. 16c) denote regions of the modeled CO plumes (Fig. 16b, d, f). Unfortunately, these areas again coincide with areas of extensive cloud cover that correspond to frontal systems. In the cloud labeled " 1 ", there are two orange layers (indicating aerosols) between 5 and $10 \mathrm{~km}$ altitude. However, a close examination of Level 1 browse images (not shown) does not indicate aerosols. Instead, there are cloud fragments that typically cause misclassifications. At the base of the cloud labeled "2", the red layer is an artifact, and the orange (aerosol) layer just below it likely is an artifact as well based on the Level 1 browse images. The vertically oriented orange layer also appears to be an artifact of the type often seen below attenuating clouds. Thus, CALIOP provides 
a)

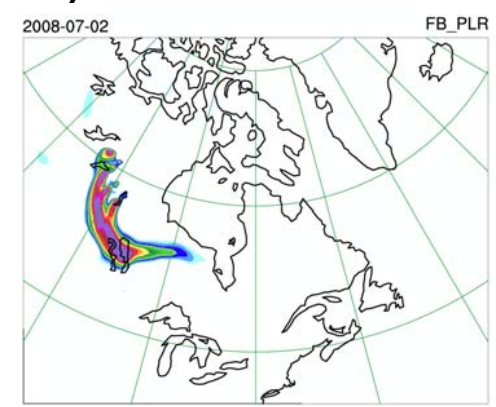

c)

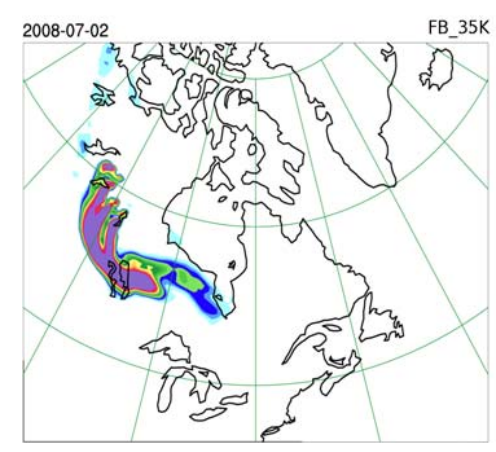

e)

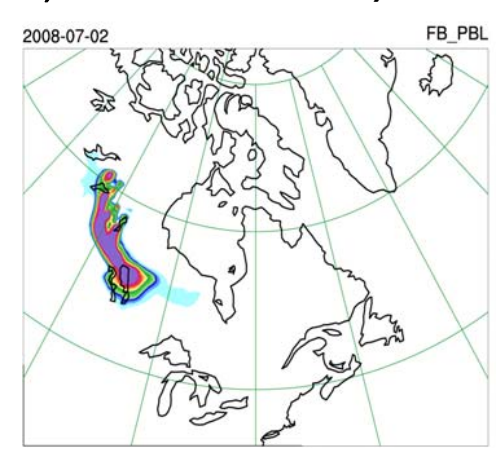

b)
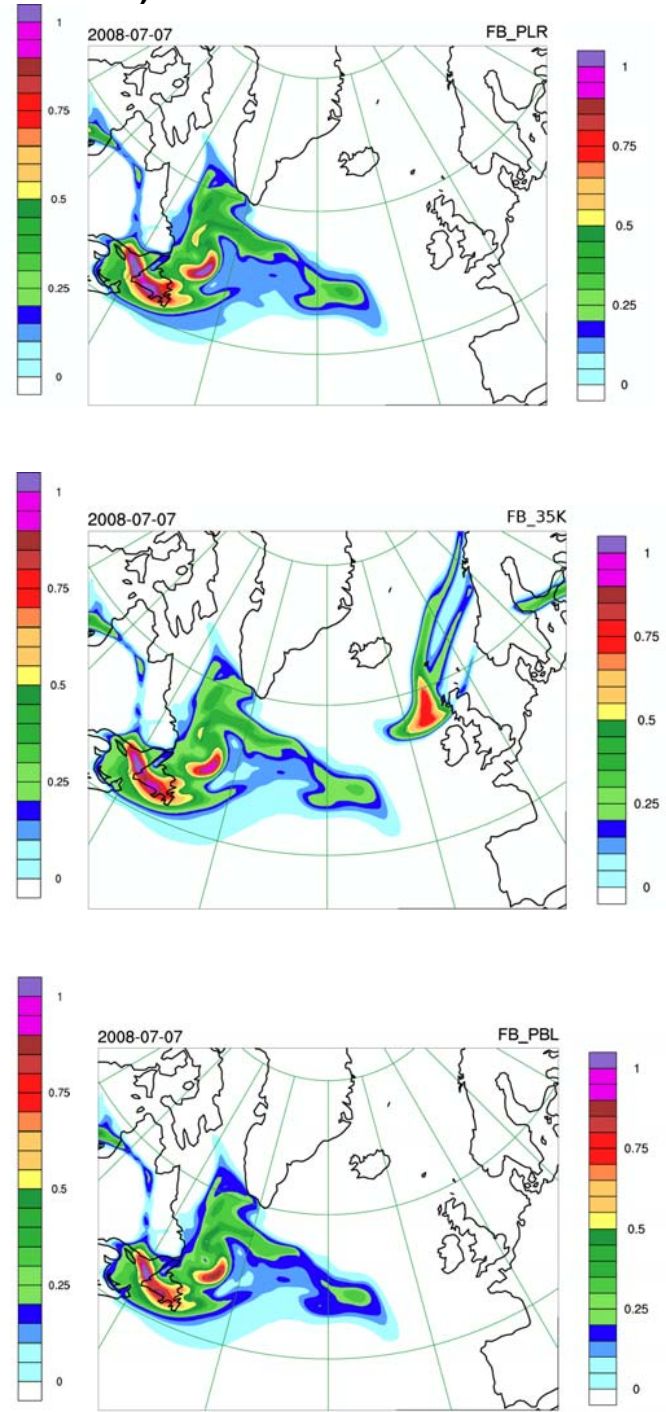

Fig. 15. Normalized WRF-Chem Total Column CO for the North American plume over Canada on (a, c, e) 2 July and (b, d, f) 7 July.

only weak evidence for enhanced aerosols at these altitudes. Nonetheless, the aerosol (orange) layers that are indicated below $3 \mathrm{~km}$ in both areas do appear valid. They are not located beneath the higher level clouds, and their aerosol designation is supported by the Level 1 browse product. Thus, the CALIOP VFM shows evidence of enhanced aerosol in the low troposphere beneath and between the higher level clouds. This horizontal location is consistent with those of the three injection procedures (Fig. 16b, d, e). However, the clouds at higher altitudes prevent solid evidence of aerosols at higher altitudes where the simulations produce maxima. Cloud cover on both 2 and 7 July again prevent reliable quantitative comparisons of the plumes with AIRS products.

\section{Summary and conclusion}

Episodic events such as boreal wildfires play an important role in the composition of the Arctic atmosphere and represent an important forcing to its radiation budget. To accurately simulate wildfire events, it is important to inject their emissions at the appropriate altitudes so they are properly transported by the wind.

This case study has examined the ability of the WRFChem online chemical transport model to diagnose the injection layers of biomass burning emissions. Ten-day simulations were performed during the Summer 2008 ARCTAS period. Three methods of injection were considered - an imbedded 1-D plume rise model at each grid point, releasing emissions within the PBL, and releasing them 
a)

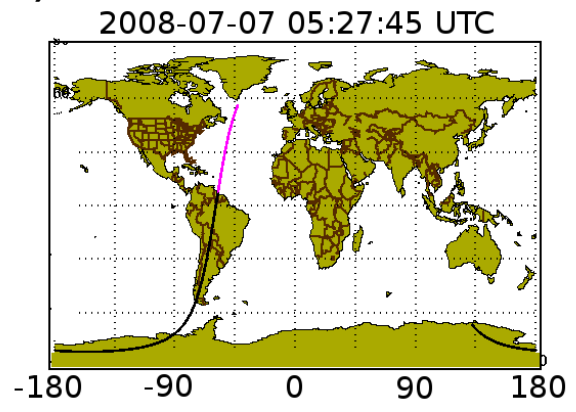

b)

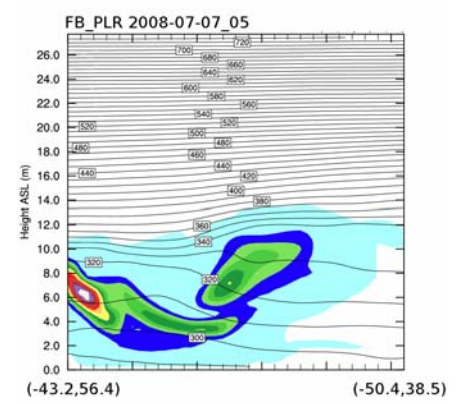

c)

d)

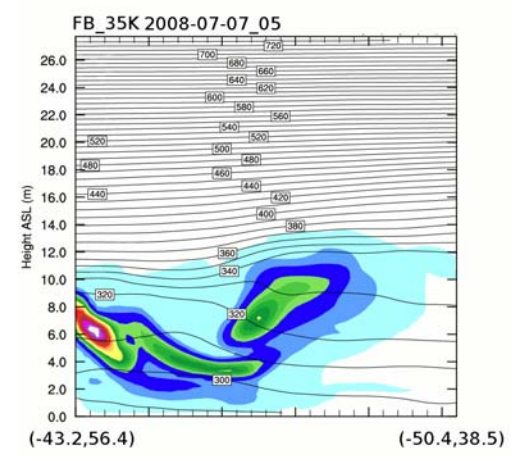

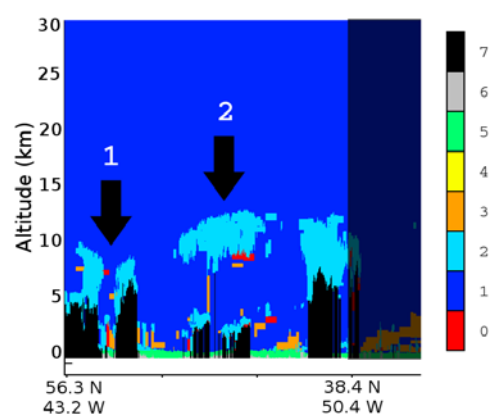

$0=1$ ow $/$ no confidence, $1=$ clear air, $2=$ cloud, $3=$ eerosol 1 $0=10 \mathrm{w} / \mathrm{no}$ confidence, $1=\mathrm{clear}$ air $, 2=\mathrm{cloud}, 3=\mathrm{aerosol}$
$4=$ stratospheric, $5=$ surface, $6=$ subsurface, $7=$ no signa

e)

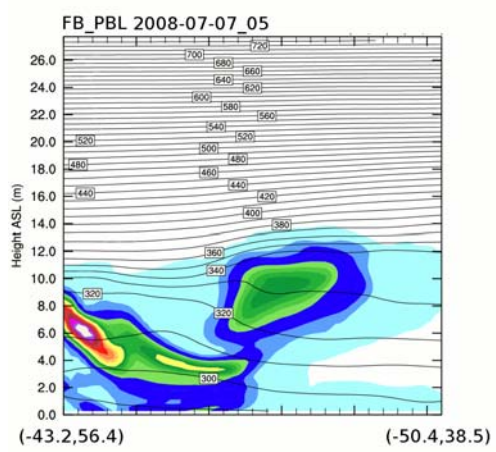

Fig. 16. (a) Map of CALIPSO path at 05:27 UTC 7 July 2008 with analyzed segment over the Atlantic Ocean in violet and (b) CALIOP vertical feature mask (VFM). Normalized WRF aerosol plume for (b) FB_PLR, (d) FB_35K, and (e) FB_PBL along the CALIPSO track. This is a descending overpass; north is to the left. Arrows in (c) indicate features discussed in the text. Numerous previous studies have released emissions between the surface and the top of the planetary boundary layer (e.g., Fisher et al., 2010; Leung et al., 2007; Hyer et al., 2007).

between $3-5 \mathrm{~km}$ above the surface. Results of the simulations were compared with AIRS-patterns of total column CO and MISR-derived aerosol plume heights, as well as downwind aerosol vertical distributions from CALIPSO. We assumed that $\mathrm{CO}$ and aerosol plumes from the wildfires were co-located.

WRF-Chem was run using two different preprocessing methods for wildfires, prep_chem_sources and FLAMBE. Prep_chem_sources produced a comparatively narrow distribution of injection heights because of the way that the plume rise model parameterizes entrainment. Plume height is reduced by entrainment, which is assumed to be inversely proportional to the burn area. The majority of the fires that were studied were identified by MODIS, to which prep_chem_sources applied a single value of burn area, regardless of time of day. This constant value limited the range of injection heights.

FLAMBE produced a wider range of injection layers that more closely agreed with the MISR-derived heights. Although FLAMBE begins with a single burn area for each detection, these areas then are modified to be proportional to the diurnal cycle of burning intensity, with size increasing 
during the afternoon and decreasing at night. The inclusion of smaller burn areas during the morning produced lower injection heights that were more consistent with those observed during MISR's morning overpass.

MISR stereo heights also were used to evaluate results from injecting the emissions confined to the planetary boundary lower, and emissions released between $3 \mathrm{~km}$ and $5 \mathrm{~km}$ a.g.l. The majority of the MISR heights were above the simulated planetary boundary layer but below the $3-5 \mathrm{~km}$ layer. These results from our ARCTAS simulations indicate that limiting injection to these layers is not ideal for the geographic and meteorological settings of the study. The majority of injection heights simulated by the WRF-Chem plume rise model were between the top of the PBL and $3 \mathrm{~km}$ a.g.l. Thus, the 1-D plume rise model produced the most realistic approximation of the top of injection layers during the study period.

Current injection heights were compared with those of previous studies. We believe that model resolution and the choice of the PBL scheme used in the model must be considered in such comparisons. We do not know of any published study that has evaluated the results from various model resolutions and numerical PBL options against observations. Such a study would be very useful in deciding which PBL methodology to use in a CTM.

Since wind direction and speed vary with altitude, different injection altitudes often lead to different transport pathways, especially when longer time periods are considered. We evaluated simulated long range plume transport both qualitatively and quantitatively against data from the AIRS and CALIOP satellite sensors. Based on our earlier results, we only used the FLAMBE dataset in this evaluation. We again considered three methods of injection (plume rise, FB_PLR; planetary boundary layer, FB_PBL; 3-5 km a.g.1., FB_35K). Results for these injection configurations were compared for four plumes: an eastern Russian plume over the Sea of Okhotsk, two cases when the northern branch of the Russian plume was transported into the Arctic, and a Canadian plume over eastern Canada and the Atlantic Ocean. Where possible, quantitative scores were produced using an object-based method in the MODE software package.

Results, as expected, showed that differences in transport between the injection methods were most prominent in situations of large vertical wind shear and when the integration period was long. The stronger vertical wind shear over Siberia than southern Canada increased the impact of the different smoke injection heights for the Siberian fires. Differences in transport were most evident in the northern branch of the Russian plume and its subsequent transport into the Arctic. The higher altitude emission layers from FB_PLR and FB_35K were transported into the Arctic, while the lower altitude FB_PBL emissions were lofted later and followed a different path. Transport into the Arctic from high-midlatitude sources was mediated by the occurrence of warm conveyer belt meteorological events, convolved with smoke injection into the appropriate levels within the atmospheric vertical structure. The satellite-derived products supported the higher altitude emission schemes over northeastern Russia and into the Arctic. MODE-derived CSI scores confirmed that the 1-D plume rise configuration produced the best agreement with the satellite observations.

Our long range transport evaluations were limited by two factors. First, satellite data were limited in heavily clouded regions such as central Canada and the Arctic. Large regions of the simulated Canadian and Arctic plumes could not be qualitatively or quantitatively compared because of cloud contamination. The presence of emissions released prior to the study period also produced observed enhancements over Canada and Russia that were not represented in the simulations. This problem could be reduced with the assimilation of satellite-derived CO data into WRF-Chem. Improvements in satellite data quality would enhance the WRF-Chem simulations during with input and later during verification.

To summarize, the 1-D plume rise model within WRFChem produced injection heights and plumes that agreed best with observed data during our case study period, although interpretation of the PBL height relative to the satelliteretrieved plume height remains an uncertainty that warrants further investigation. The greatest differences between injection methods occurred in cases of relatively strong vertical wind shear and when the integration period was long. The 1-D plume model was developed for use in low resolution models such as global CTMs, but can be used at higher resolutions such as we have done here. Our experience is that it does not require significant additional computing time compared to procedures that make major assumptions about injection height. Previous studies and current results suggest that embedded plume models are a valuable addition to our arsenal of methodologies. The current results should be considered a case study of a small period during the Arctic summer. Additional studies should be performed to determine whether they are applicable to other regions and meteorological conditions.

Acknowledgements. This research was sponsored by NASA's Global Tropospheric Chemistry Program through Grant NNX08AH72G to Florida State University. We appreciate the helpful information provided by Michael Fromm and Juying Warner. We also appreciate the assistance of the many individuals who made ARCTAS a success - the ground crew, pilots, supporting staff, and other members of the ARCTAS Science Team. Two anonymous reviewers as well as Maria Val Martin provided valuable information that greatly improved the manuscript.

Edited by: A. Stohl 


\section{References}

Ackermann, I. J., Hass, H., Memmesheimer, M., Ebel, A., Binkowski, F. S., and Shankar, U.: Modal aerosol dynamics model for Europe: Development and first applications. Atmos. Environ., 32, 2981-2999, 1998.

Andreae, M. O. and Merlet, P.: Emission of trace gases and aerosols from biomass burning, Global Biogeochem. Cy., 15, 955-966, 2001.

Andreae, M. O., Rosenfeld, D., Artaxo, P., Costa, A. A., Frank, G. P., Longo, K. M., and Silva-Dias, M. A. F.: Smoking rain clouds over the Amazon, Science, 303, 1337-1342, 2004.

Arctic Climate Impact Assessment, Impacts of a Warming Arctic: Arctic Climate Impact Assessment, Cambridge Univ. Press, New York, 2004.

Barrie, L. A.: Arctic air pollution: An overview of current knowledge, Atmos. Environ., 20, 643-663, 1986.

Berry, E. X.: Modification of the warm rain process, Preprints, 1st Natl. Conf. on Weather Modification, Amer. Meteor. Soc., Albany, NY, 81-88, 1968.

Brioude, J., Cooper, O. R., Feingold, G., Trainer, M., Freitas, S. R., Kowal, D., Ayers, J. K., Prins, E., Minnis, P., McKeen, S. A., Frost, G. J., and Hsie, E.-Y.: Effect of biomass burning on marine stratocumulus clouds off the California coast, Atmos. Chem. Phys., 9, 8841-8856, doi:10.5194/acp-9-8841-2009, 2009.

Bethan, S., Vaughan, G., Gerbig, C., Volz-Thomas, A., Richer, H., and Tiddeman, D.: Chemical air mass differences near fronts, J. Geophys. Res., 103(D11), 13413-13434, 1998.

Chang, J. S., Binkowski, F. S., Seaman, N. L., McHenry, J. N., Samson, P. J., Stockwell, W. R., Walcek, C. J., Madronich, S., Middleton, P. B., Pleim, J. E., and Lansford, H. H.: The regional acid deposition model and engineering model. State-ofScience/Technology, Report 4, National Acid Precipitation Assessment Program, Washington, DC, 1991.

Chou M.-D. and Suarez, M. J.: An efficient thermal infrared radiation parameterization for use in general circulation models, NASA Tech. Memo. 104606, 3, 85 pp., 1994.

Cofer, W. R., Winstead, E. L., Stocks, B. J., Overbay, L. W., Goldammer, J. G., and Cahoon, D.: Emissions from boreal forest fires: Are the atmospheric impacts underestimated? In: Biomass Burning and Global Change, edited by: Levine, J. S., MIT Press, Cambridge, MA, 834-839, 1996.

Colarco, P. R., Schoeberl, M. R., Doddridge, B. G., Marufu, L. T., Torres, O., and Welton, E. J.: Transport of smoke from Canadian forest fires to the surface near Washington, D. C.: Injection height, entrainment, and optical properties, J. Geophys. Res., 109, D06203, doi:10.1029/2003JD004248, 2004.

Cooper, O.R., Forster, C., Parrish, D., Trainer, M., Dunlea, E., Ryerson, T., Hübler, G., Fehsenfeld, F., Nicks, D., Holloway J., De Gouw, J., Warneke, C., Roberts, J.M., Flocke. F., and Moody, J. : A case study of transpacific warm conveyor belt transport: Influence of merging airstreams on trace gas import to North America, J. Geophys. Res., 109, D23S08, doi:10.1029/2003JD003624, 2004.

Crawford, J., Olson, J., Davis, D., Chen, G., Barrick, J., Shetter, R., Lefer, B., Jordan, C., Anderson, B., Clarke, A., Sachse, G., Blake, D., Singh, H., Sandholm, S., Tan, D., Kondo, Y., Avery, M., Flocke, F., Eisele, F., Mauldin, L., Zondlo, M., Brune, W., Harder, H., Martinez, M., Talbot, R., Bandy, A., and Thornton, D.: Clouds and trace gas distributions during TRACE-P, J. Geo- phys. Res., 108, 8829, doi:10.1029/2002JD003232, 2003.

Crutzen, P. J. and Andreae, M. O.: Biomass burning in the tropicsImpact on atmospheric chemistry and biogeochemical cycles, Science, 250, 4898, 1669-1678, 1990.

Damoah, R., Spichtinger, N., Forster, C., James, P., Mattis, I., Wandinger, U., Beirle, S., Wagner, T., and Stohl, A.: Around the world in 17 days - hemispheric-scale transport of forest fire smoke from Russia in May 2003, Atmos. Chem. Phys., 4, 13111321, doi:10.5194/acp-4-1311-2004, 2004.

Davis, C., Brown, B., and Bullock, R., Object-based verification of precipitation forecasts. Part I: Methodology and application to mesoscale rain areas, Mon Weather Rev., 134, 1772-1784, 2006.

Davis, C. A., Brown, B. G., Bullock, R., and HalleyGotway, J.:The method for object-based diagnostic evaluation (MODE) applied to numerical forecasts from the 2005 NSSL/SPC spring program, Weather Forecast., 24, 1252-1267, doi:10.1175/2009WAF2222241.1, 2009.

Dickerson , R. R., Li, C., Li, Z., Marufu, L.T., Stehr, J.W., McClure, B., Krotkov, N., Chen, H., Wang, P., Xia, X., Ban, X. Gong, F., Yuan, J., and Yang, J.: Aircraft observations of dust and pollutants over northeast China: Insight into the meteorological mechanisms of transport, J. Geophys. Res., 112, D24S90, doi:10.1029/2007JD008999, 2007.

Diner, D. J., Davies, R., DiGirolamo, L., Horvath, A., Moroney, C., Muller, J. P., Paradise, S. R., Wenkert, D., and Zong, J.: MISR level 2 cloud detection and classification algorithm theoretical basis, JPL D-11399, Rev. D, Jet Propulsion Laboratory, California Institute of Technology, 1999.

Ding, A., Wang, T., Xue, L. K., Gao, J., Stohl, A., Lei, H. C., Jin, D. Z., Ren, Y., Wang, X. Z., Wei, Z. L., Qi, Y. B., Liu, J., and Zhang, X. Q.: Transport of north China air pollution by midlatitude cyclones: Case study of aircraft measurements in summer 2007, J. Geophys. Res., 114, D08304, doi:10.1029/2008JD011023, 2009.

Dyer, A. J. and Hicks, B. B.: Flux-gradient relationships in the constant flux layer, Q. J. Roy. Meteorol. Soc., 96, 715-721, 1970.

Eckhardt, S., Stohl, A., Wernli, H., James, P., Forster, C., and Spichtinger, N.: A 15-year climatology of warm conveyor belts, J. Climate, 17, 218-237, 2004.

Ek, M. B., Mitchell, K. E., Lin, Y., Rogers, E., Grunmann, P., Koren, V., Gayno, G., and Tarpley, J. D.: Implementation of Noah land surface model advances in the National Centers for Environmental Prediction operational mesoscale Eta model, J. Geophys. Res., 108, 8851, doi:10.1029/2002JD003296, 2003.

Fisher, J. A., Jacob, D. J., Purdy, M. T., Kopacz, M., Le Sager, P., Carouge, C., Holmes, C. D., Yantosca, R. M., Batchelor, R. L., Strong, K., Diskin, G. S., Fuelberg, H. E., Holloway, J. S., Hyer, E. J., McMillan, W. W., Warner, J., Streets, D. G., Zhang, Q., Wang, Y., and Wu, S.: Source attribution and interannual variability of Arctic pollution in spring constrained by aircraft (ARCTAS, ARCPAC) and satellite (AIRS) observations of carbon monoxide, Atmos. Chem. Phys., 10, 977-996, doi:10.5194/acp-10-977-2010, 2010.

Forster, C., Wandinger, U., Wotawa, G., James, P., Mattis, I., Althausen, D., Simmonds, P., O'Doherty, S., Jennings, S.F., Kleefeld, C., Schneider, J., Trickl, T., Kreipl, S., Jager, H., and Stohl, A.: Transport of boreal forest fire emissions from Canada to Europe, J. Geophys. Res., 106(D19), 22887-22906, 2001.

Freitas, S. R., Longo, K. M., and Andreae, M. O.: The impact of including the plume rise of vegetation fires in numerical simula- 
tions of associated atmospheric pollutants, Geophys. Res. Lett., 33, L17808, doi:10.1029/2006GL026608, 2006.

Freitas, S. R., Longo, K. M., Chatfield, R., Latham, D., Silva Dias, M. A. F., Andreae, M. O., Prins, E., Santos, J. C., Gielow, R., and Carvalho Jr., J. A.: Including the sub-grid scale plume rise of vegetation fires in low resolution atmospheric transport models, Atmos. Chem. Phys., 7, 3385-3398, doi:10.5194/acp-7-33852007, 2007.

Freitas, S. R., Longo, K. M., Trentmann, J., and Latham, D.: Technical Note: Sensitivity of 1-D smoke plume rise models to the inclusion of environmental wind drag, Atmos. Chem. Phys., 10, 585-594, doi:10.5194/acp-10-585-2010, 2010.

Fromm, M., Shettle, E. P., Fricke, K. H. Ritter, C., Trickl, T., Giehl, H., Gerding, M., Barnes, J. E., O’Neill, M., Massie, S. T. Blum, U., McDermid, I. S., Leblanc, T., and Deshler, T.: Stratospheric impact of the Chisholm pyrocumulonimbus eruption: 2. Vertical profile perspective, J. Geophys. Res., 113, D08203, doi:10.1029/2007JD009147, 2008.

Fuelberg, H. E., Harrigan, D. L., and Sessions, W.: A meteorological overview of the ARCTAS 2008 mission, Atmos. Chem. Phys., 10, 817-842, doi:10.5194/acp-10-817-2010, 2010.

Garrett, Tim: Pollutant Haze is Heating up the Arctic, available at: http://earthobservatory.nasa.gov/Newsroom/view.php? id=30036, 10 May 2006.

Generoso, S., Bey, I., Attie, J.-L., and Breon, F.-M.: A satelliteand model-based assessment of the 2003 Russian fires: Impact on the Arctic Region, J. Geophys. Res., 112, D15302, doi:10.1029/2006JD008344, 2007.

Giglio, L., Descloitres, J., Justice, C. O., and Kaufman, Y. L.: An enhanced contextual fire detection algorithm for MODIS, Remote Sens. Environ., 87, 273-282, doi:10.1016/S00344257(03)00184-6, 2003.

Global Climate and Weather Modeling Branch: The GFS Atmospheric Model. NOAA/NWS/NCEP Office Note 442, 14 pp., 2003.

Grell, G. A. and Devenyi, D.: A generalized approach to parameterizing convection combining ensemble and data assimilation techniques, Mon. Weather Rev., 121, 764-787, 2002.

Grell, G. A., Peckham, S. E., Schmitz, R., McKeen, S. A., Frost, G., Skamarock, W. C., and Eder, B.: Fully coupled "online" chemistry within the WRF model, Atmos. Environ., 39, 6957-6975, doi:10.1016/j.atmosenv.2005.04.027, 2005.

Grell, G., Freitas, S. R., Stuefer, M., and Fast, J.: Inclusion of biomass burning in WRF-Chem: impact of wildfires on weather forecasts, Atmos. Chem. Phys., 11, 5289-5303, doi:10.5194/acp-11-5289-2011, 2011.

Hansen, J. and Nazarenko, L.: Soot climate forcing via snow and ice albedos, P. Natl. Acad. Sci., 101, 423-428, 2004.

Hegg, D. A., Warren, S. G., Grenfell, T. C., Doherty, S. J., Larson, T. V., and Clarke, A. D.: Source attribution of black carbon in arctic snow, Environ. Sci. Technol., 43, 4016-4021, doi:10.1021/es803623f, 2009.

Hong, S.-Y. and Pan, H. L.: Nonlocal boundary layer vertical diffusion in a medium-range forecast model, Mon. Weather Rev., 124, 2322-2339, 1996.

Hong, S.-Y., Noh, Y., and Dudhia, J.: A new vertical diffusion package with an explicit treatment of entrainment processes, Mon. Weather Rev., 134, 2318-2341, 2006.

Hyer, E. J., Allen, D. J., and Kasischke, E. S.: Examining injec- tion properties of boreal forest fires using surface and satellite measurements of CO transport, J. Geophys. Res., 112, D18307, doi:10.1029/2006JD008232, 2007.

Jacob, D. J., Crawford, J. H., Maring, H., Clarke, A. D., Dibb, J. E., Emmons, L. K., Ferrare, R. A., Hostetler, C. A., Russell, P. B., Singh, H. B., Thompson, A. M., Shaw, G. E., McCauley, E., Pederson, J. R., and Fisher, J. A.: The Arctic Research of the Composition of the Troposphere from Aircraft and Satellites (ARCTAS) mission: design, execution, and first results, Atmos. Chem. Phys., 10, 5191-5212, doi:10.5194/acp-10-5191-2010, 2010.

Jaffe, D., Anderson, T., Covert, D., Kotchenruther, R., Trost, B., Danielson, J., Simpson, W., Berntsen, T., Karlsdottir, S., Harris, J., Carmichael, G., and Uno, I.: Transport of Asian air pollution to North America, Geophys. Res. Lett., 26, 711-714, doi:10.1029/1999GL900100, 1999.

Jaffe, D., Price, H., Parrish, D., Goldstein, A., and Harris, J. A.: Increasing background ozone during spring on the west coast of North America, Geophys. Res. Lett., 30, 1613, doi:10.1029/2003GL017024, 2003.

Jordan, N. S., Hoff, R. M., and Bacmeister, J. T.: Validation of Goddard Earth Observing System-version 5 MERRA planetary boundary layer heights using CALIPSO, J. Geophys. Res., 115, D24218, doi:10.1029/2009JD013777, 2010.

Justice, C. O., Giglio, L., Korontzi, S., Owens, J., Morisette, J. T., Roy, D., Descloitres, J., Alleaume, S., Petitcolin, F., and Kaufman, Y.: The MODIS fire products, Remote Sens. Environ., 83, 244-262, 2002.

Kahn, R. A., Li, W.-H., Moroney, C., Diner, D. J., Martonchik, J. V., and Fishbein, E.: Aerosol source plume physical characteristics from space-based multiangle imaging, J. Geophys. Res., 112, D11205, doi:10.1029/2006JD007647, 2007.

Kahn, R. A., Chen, Y., Nelson, D. L., Leung, F. Y., Li, Q. B., Diner, D. J., and Logan, J. A.: Wildfire smoke injection heights: two perspectives from space, Geophys. Res. Lett., 35, L04809, doi:10.1029/2007GL032165, 2008.

Kasischke, E. S. and Bruhwiler, L. P.: Emissions of carbon dioxide, carbon monoxide, and methane from boreal forest fires in 1998, J. Geophys. Res., 107, 8146, doi:10.1029/2001JD000461, 2002.

Kasischke, E. S., Hyer, E. J., Novelli, P. C., Bruhwiler, L. P., French, N. H. F., Sukhinin, A. I., Hewson, J. H., and Stocks, B. J.: Influences of boreal fire emissions on Northern Hemisphere atmospheric carbon and carbon monoxide, Global Biogeochem. Сy., 19, GB1012, doi:10.1029/2004GB002300, 2005.

Kessler, E.: On the distribution and continuity of water substance in atmospheric circulations, Meteor. Monographs, 10, Amer. Meteor. Soc., Boston, MA, 1969.

Kiley, C. M. and Fuelberg, H. E.: An examination of summertime cyclone transport processes during intercontinental chemical transport experiment (INTEX-A), J. Geophys. Res., 111, D24S06, doi:10.1029/2006JD007115, 2006.

Klonecki, A., Hess, P., Emmons, L., Smith, L., Orlando, J., and Blake, D.: Seasonal changes in the transport of pollutants into the Arctic troposphere-model study, J. Geophys. Res., 108, 8367, doi:10.1029/2002JD002199, 2003.

Koch, D. and Hansen, J.: Distant origins of Arctic black carbon: A Goddard Institute for Space Studies Model Experiment, J. Geophys. Res., 110, 4204, doi:10.1029/2004JD005296, 2005.

Labonne, M., Breon, F.-M., and Chevallier, F.: Injection height of biomass burning aerosols as seen from a spaceborne lidar, Geo- 
phys. Res. Lett., 34, L11806, doi:10.1029/2007GL029311, 2007.

Lamarque, J. F., Edwards, D. P., Emmons, L. K., Gille, J. C., Wilhelmi, O., Gerbig, C., Prevedel, D., Deeter, M. N., Warner, J., Zeskin, D. C., Khattatov, B., Francis, G. L., Yudin, V., Ho, S., Mao, D., Chen, J., and Drummond, J. R.: Identification of CO plumes from MOPPITT data: Application to the August 2000 Idaho-Montana forest fires, Geophys. Res. Lett., 30, 1688, doi:10.1029/2003GL017503, 2003.

Latham, D.: PLUMP: A one-dimensional plume predictor and cloud model for fire and smoke managers, General Technical Report INT-GTR-314, Intermountain Research Station, USDA Forest Service, November, 1994.

Lavouè, D., Liousse, C., Cachier, H., Stocks, B. J., and Goldammer, J. G.: Modeling of carbonaceous particles emitted by boreal and temperate wildfires at northern latitudes, J. Geophys. Res., 105, 26871-26890, 2000.

Law, K. S. and Stohl, A.: Arctic Air Pollution: Origins and Impacts, Science, 315, 1537-1540, 2007.

Leung , F.-Y. T., Logan, J. A., Park, R., Hyer,E., Kasischke, E., Streets, D., and Yurganov, E.: Impacts of enhanced biomass burning in the boreal forests in 1998 on tropospheric chemistry and the sensitivity of model results to the injection height of emissions, J. Geophys. Res., 112, D10313, doi:10.1029/2006JD008132, 2007.

Liang, Q., Jaeglé, L., Jaffe, D. A., Weiss-Penzias, P., Heckman, A., and Snow, J. A.: Long-range transport of Asian pollution to the northeast Pacific: Seasonal variations and transport pathways of carbon monoxide, J. Geophys. Res., 109, D23S07, doi:10.1029/2003JD004402, 2004.

Liu, S. C., McKeen, S. A., Hsie, E. Y., Lin, X., Kelly, K. K., Bradshaw, J. D., Sandholm, S. T., Browell, E. V., Gregory, G. L., Sachse, G. W., Bandy, A. R., Thornton, D. C., Blake, D. R., Rowland, F. S., Newell, R., Heikes, B. G., Singh H., and Talbot, R. W.: Model study of tropospheric trace species distributions during PEM-West A, J. Geophys. Res., 101, 2073-2085, 1996.

Lucchesi, R.: File Specification for GEOS-5 DAS Gridded Output Global Modeling and Assimilation Office Version 6.3, Goddard Space Flight Center, Greenbelt, Maryland, available at: http:// gmao.gsfc.nasa.gov/operations/GEOS5V1FileSpecification.pdf, 2007.

Mass, C. F., Ovens, D., Westrick, K., and Colle, B. A.: Does Increasing Horizontal Resolution Produce More Skillful Forecasts? The results of two years of real-time numerical weather prediction over the Pacific northwest, B. Am. Meteorol. Soc., 83, 407430, 2002

Matson, M. and Dozier, J.: Identification of subresolution high temperature sources using a thermal IR sensor, Photogramm. Eng. Rem. S., 47, 1311-1318, 1981.

McConnell, J. R., Edwards, R., Kok, G. L., Flanner, M. G., Zender, C. S., Saltzman, E. S., Banta, J. R., Pasteris, D. R., Carter, M. M., and Kahl, J. D. W.: 20th-century industrial black carbon emissions altered arctic climate forcing, Science, 317, 1381, doi:10.1126/science.1144856, 2007.

McMillan, W. W., Barnet, C., Strow, L., Chahine, M. T., McCourt, M. L., Warner, J. X., Novelli, P. C., Korontzi, S., Maddy, E. S., and Datta, S.: Daily global maps of carbon monoxide from NASA's Atmospheric Infrared Sounder, Geophys. Res. Lett., 32, L11801, doi:10.1029/2004GL021821, 2005.

Mitchell Jr., J. M.: Visual range in the polar regions with particular reference to the Alaskan Arctic, J. Clim. Appl. Meteor., 23, 916928, 1957.

Miyazaki, Y., Kondo, Y., Koike, M., Fuelberg, H. E., Kiley, C. M., Kita, K., Takegawa, N., Sachse, G. W., Flocke, F., Weinheimer, A. J., Singh, H. B., Eisele, F. L., Zondlo, M., Talbot, R. W., Sandholm, S. T., Avery, M. A., and Blake, D. R.: Synoptic-scale transport of reactive nitrogen over the western Pacific in spring, J. Geophys. Res., 108, 8788, doi:10.1029/2002JD003248, 2003.

Mlawer, E. J., Taubman, S. J., Brown, P. D., Iacono, M. J., and Clough, S. A.: Radiative transfer for inhomogeneous atmosphere: RRTM, a validated correlated-k model for the long-wave, J. Geophys. Res., 102(D14), 16663-16682, 1997.

Muller, J.-P., Mandanayake, A., Moroney, C., Davies, R., Diner, D. J., and Paradise, S.: MISR stereoscopic image matchers: techniques and results, IEEE T. Geosci. Remote., 40, 1547-1559, 2002.

Nelson, D. L., Chen, Y., Kahn, R. A., Diner, D. J., and Mazzoni, D.: Example applications of the MISR INteractive eXplorer (MINX) software tool to wildfire smoke plume analyses, Proc. SPIE, 7089, 708909.1-708909.11, 2008.

Ogura, Y. and Takahashi, T.: Numerical simulation of the life cycle of a thunderstorm cell, Mon. Weather Rev., 99, 895-911, 1971.

Pagowski, M.: Some comments on PBL parameterizations in WRF, The Joint WRF/MM5 Users' Workshop, Boulder, CO, 2004.

Palm, S. P., Benedetti, A., and Spinhirne, J.: Validation of ECMWF global forecast model parameters using GLAS atmospheric channel measurements, Geophys. Res. Lett., 32, L22S09, doi:10.1029/2005GL023535, 2005.

Paulson, C. A.: The mathematical representation of wind speed and temperature profiles in the unstable atmospheric surface layer, J. Appl. Meteor., 9, 857-861, 1970.

Peffers, L. T., Fuelberg, H. E., and Rao, P. A.: Evaluation of smoke plume dispersion in complex terrain using a Lagrangian particle dispersion model driven by WRF output. 11th Conf. Atmos. Chemistry, Amer. Meteor. Soc., Phoenix, Paper 3.6, 2009.

Quinn, P. K., Shaw, G., Andrews, E., Dutton, E. G., RuohoAirola, T., and Gong, S. L.: Arctic haze: current trends and knowledge gaps, Tellus, 59, 99-114, doi:10.1111/j.16000889.2006.00238.x, 2007.

Quinn, P. K., Bates, T. S., Baum, E., Doubleday, N., Fiore, A. M., Flanner, M., Fridlind, A., Garrett, T. J., Koch, D., Menon, S., Shindell, D., Stohl, A., and Warren, S. G.: Short-lived pollutants in the Arctic: their climate impact and possible mitigation strategies, Atmos. Chem. Phys., 8, 1723-1735, doi:10.5194/acp8-1723-2008, 2008.

Reid, J., Hyer, E. J., Prins, E. M., Westphal, D. L., Zhang, J., Wang, J., Christopher, S. A., Curtis, C. A., Schmidt, C. A., Eleuterio, D. P., Richardson, K. A., and Hoffman, J. P.: Global Monitoring and Forecasting of Biomass-Burning Smoke: Description of and Lessons From the Fire Locating and Modeling of Burning Emissions (FLAMBE) Program, IEEE J. Sel. Top. Appl., 2, 2009.

Schell, B., Ackermann, I. J., Hass, H., Binkowski, F. S., and Ebel, A.: Modeling the formation of secondary organic aerosol within a comprehensive air quality model system, J. Geophys. Res., 106, 28275-28293, 2001.

Schultz, M. G., Heil, A., Hoelzemann, J. J., Spessa, A., Thonicke, K., Goldammer, J. G., Held, A. C., Pereira, J. M. C., and van het Bolscher, M.: Global wildland fire emissions from 1960-2000, Global Biogeochem. Cy., 22, GB2002, 
doi:10.1029/2007GB003031, 2008.

Sharma, S., Andrews, E., Barrie, L. A., Ogren, J. A., and Lavoué, D, J.: Variations and sources of the equivalent black carbon in the high Arctic revealed by long-term observations at Alert and Barrow: 1989-2003, J. Geophys. Res., 111, D14208, doi:10.1029/2005JD006581, 2006.

Shaw, G. E.: The Arctic haze phenomenon, B. Am. Meteorol. Soc., 76, 2403-2413, 1995.

Skamarock, W. C., Klemp, J. B., Dudhia, J., Gill, D. O., Barker, D. M., Duda, M., Huang, X.-Y., Wang, W., and Powers, J. G.: A Description of the Advanced Research WRF Version 3, NCAR Technical Note, 2008.

Solberg, S., Dye, C., Schmidbauer, N., Herzog, A., and Gehrig, R.: Carbonyls and non-methane hydrocarbons at rural European sites from the Mediterranean to the Arctic, J. Atmos. Chem., 25, 33-66, 1996.

Spichtinger, N., Wenig, M., James, P., Wagner, T., Platt, U., and Stohl, A.: Satellite detection of a continental-scale plume of nitrogen oxides from boreal forest fires, Geophys. Res. Lett., 28, 4579-4582, 2001.

Stocks, B. J., Mason, J. A., Todd, J. B., Bosch, E. M., Wotton, B. M., Amiro, B. D., Flannigan, M. D., Hirsch, K. G., Logan, K. A., Martell, D. L., and Skinner, W. R.: Large forest fires in Canada, 1959-1997, Geophys. Res. Lett., 108, 8149, doi:10.1029/2001JD000484, 2003.

Stohl, A.: A 1-year Lagrangian "climatology" of airstreams in the Northern Hemisphere troposphere and lowermost stratosphere, J. Geophys. Res., 106, 7263-7279, 2001.

Stohl, A.: Characteristics of atmospheric transport into the Arctic troposphere, J. Geophys. Res., 111, D11306, doi:10.1029/2005JD006888, 2006.

Stohl, A., Wotawa, G., Seibert, P., and Kromp-Kolb, H.: Interpolation errors in wind fields as a function of spatial and temporal resolution and their impact on different types of kinematic trajectories, J. Appl. Meteor., 34, 2149-2165, 1995.

Stohl, A., Hittenberger, M., and Wotawa, G.: Validation of the Lagrangian particle dispersion model FLEXPART against large scale tracer experiments, Atmos. Environ. 32, 4245-4264, 1998.

Stohl, A., Forster, C., Frank, A., Seibert, P., and Wotawa, G.: Technical note: The Lagrangian particle dispersion model FLEXPART version 6.2, Atmos. Chem. Phys., 5, 2461-2474, doi:10.5194/acp-5-2461-2005, 2005.

Stohl, A., Forster, C., Huntrieser, H., Mannstein, H., McMillan, W. W., Petzold, A., Schlager, H., and Weinzierl, B.: Aircraft measurements over Europe of an air pollution plume from Southeast Asia - aerosol and chemical characterization, Atmos. Chem. Phys., 7, 913-937, doi:10.5194/acp-7-913-2007, 2007.

Trentmann, J., Luderer, G., Winterrath, T., Fromm, M. D., Servranckx, R., Textor, C., Herzog, M., Graf, H.-F., and Andreae, M. O.: Modeling of biomass smoke injection into the lower stratosphere by a large forest fire (Part I): reference simulation, Atmos. Chem. Phys., 6, 5247-5260, doi:10.5194/acp-65247-2006, 2006.

Troen, I. and Mahrt, L.: A simple model of the atmospheric boundary layer-Sensitivity to surface evaporation, Bound. Lay. Meteor., 37, 129-148, 1986.

Turner, J. S.: Buoyancy effects in fluids, Cambridge Univ. Press, Cambridge, 368 pp., 1973.
Turquety, S., Logan, J., Jacob, D., Hudman, R., Leung, F., Heald, C., Yantosca, R., Wu, S., Emmons,L., Edwards, D., and Sachse, G.: Inventory of boreal fire emissions for North America in 2004: Importance of peat burning and pyroconvective injection, J. Geophys. Res., 112, D12S03, doi:10.1029/2006JD007281, 2007.

Val Martin, M., Logan, J. A., Kahn, R. A., Leung, F.-Y., Nelson, D. L., and Diner, D. J.: Smoke injection heights from fires in North America: analysis of 5 years of satellite observations, Atmos. Chem. Phys., 10, 1491-1510, doi:10.5194/acp-10-14912010, 2010.

van der Werf, G., Randerson, J. T., Collatz, G. J., and Giglio, L.: Carbon emissions from fires in tropical and subtropical ecosystems, Glob. Change Biol., 9, 547-562, 2003.

Vaughan, M., Young, S., Winker, D., Powell, K., Omar, A., Liu, Z., Hu, Y., and Hostetler, C.: Fully automated analysis of spacebased lidar data: an overview of the CALIPSO retrieval algorithms and data products. Proc. SPIE, 5575, 16-30, 2004.

Wang, J., Christopher, S. A., Nair, U. S., Reid, J. S., Prins, E. M., Szykman, J., and Hand, J. L.: Mesoscale modeling of Central American smoke transport to the United States: 1. "Top-down" assessment of emission strength and diurnal variation impacts, J. Geophys. Res., 111, D05S17, doi:10.1029/2005JD006416, 2006.

Warneke, C., Bahreini, R., Brioude, J., Brock, C. A., de Gouw J. A., Fahey, D. W., Froyd, K. D., Middlebrook, A., Miller, L., Montzka, S., Murphy, D. M., Peischl, J., Ryerson, T. B., Schwarz, J. P., Spackman, J. R., and Veres, P.: Geophys. Res. Lett., 36, L02813, doi:10.1029/2008GL036194, 2009.

Warner, T. T., Peterson, R. A., and Treadon, R. E.: A tutorial on lateral boundary conditions as a basic and potentially serious limitation to regional numerical weather prediction, B. Am. Meteorol. Soc., 78, 2599-2617, 1997.

Westphal, D. L. and Toon, O. B.: Simulations of microphysical, radiative, and dynamical processes in a continental-scale forest fire smoke plume, J. Geophys. Res., 96, 22379-22422, 1991.

Wild, O. and Akimoto, H.: Intercontinental transport of ozone and its precursors in a three-dimensional global CTM, J. Geophys. Res., 106, 27729-27744, 2001.

Winker, D. M., Pelon, J., Coakley Jr., J. A., Ackerman, S. A., Charlson, R. J., Colarco, P. R., Flamant, P., Fu, Q., Hoff, R. M., Kittaka, C., Kubar, T. L., Le Treut, H., Mccormick, M. P., Mégie, G., Poole, L., Powell, K., Trepte, C., Vaughan, M. A., and Wielicki, B. A.: The CALIPSO Mission: A global 3-D view of aerosols and clouds, B. Am. Meteorol. Soc., 91(9), 1211-1229, 2010.

Wotawa, G., De Geer, L.-E., Becker, A., Amours, R. D'., Jean, M., Servranckx, R., and Ungar, K.: Inter- and intra-continental transport of radioactive cesium released by boreal forest fires, Geophys. Res. Lett., 33, L12806, doi:10.1029/2006GL026206, 2006.

Zhang, L., Jacob, D. J., Boersma, K. F., Jaffe, D. A., Olson, J. R., Bowman, K. W., Worden, J. R., Thompson, A. M., Avery, M. A., Cohen, R. C., Dibb, J. E., Flock, F. M., Fuelberg, H. E., Huey, L. G., McMillan, W. W., Singh, H. B., and Weinheimer, A. J.: Transpacific transport of ozone pollution and the effect of recent Asian emission increases on air quality in North America: an integrated analysis using satellite, aircraft, ozonesonde, and surface observations, Atmos. Chem. Phys., 8, 6117-6136, doi:10.5194/acp-8-6117-2008, 2008. 